\title{
Sahnede Şehirler! Türkiye'nin UNESCO Yaratıcı Şehirler Ağı - Film Alanı Açısından Değerlendirilmesi
}

\author{
Doktorant Çağla Aslı Gülduran ${ }^{1}$ \\ Doç. Dr. Işıl Arıkan Saltık ${ }^{2 *}$
}

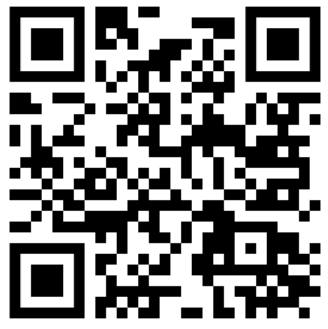

Geliş tarihi: 19.09 .2020

Kabul tarihi: 16.11 .2020

\section{Atıf bilgisi:}

IBAD Sosyal Bilimler Dergisi

Sayı: Özel Sayı Sayfa: 335-358

Yıl: 2020

This article was checked by Turnitin. Similarity Index $08 \%$

Bu makalede araştırma ve yayın etiğine uyulmuştur.

1 Muğla Sttk1 Koçman Üniversitesi,
Türkiye, caglasli87@hotmail.com, ORCID ID 0000-0002-3364-457X

2 Muğla Sıtk1 Koçman Üniversitesi, Türkiye, isilas@mu.edu.tr, ORCID ID 0000-0002-3456-2787

\footnotetext{
* Sorumlu yazar
}

ÖZ

UNESCO Yaratıcı Şehirler Ağı (UNESCO Creative Cities Network-UCCN), 2004 yılında UNESCO tarafindan, yaratıcılı̆̆ kentsel gelişme sürecinde önemli bir faktör olarak gören şehirlerarasındaki işbirliğini artırmak için gerçekleştirilen proje sonucunda kurulmuştur. Projenin ana amacı, küreselleşmenin etkisi ile ortaya çıkan kültürün homojenize olması ve metalaşması tehditlerine karşı kültür ve yaratıcılığın gelişimini teşvik etmektir. Ayrıca, işbirliği ağı aracılığıyla şehirlerin uluslararası düzeyde tanıtımına ve gelişimine katkı sağlamayı, hem küresel, hem ulusal hem de yerel düzeyde sürdürülebilir kalkınmayı desteklemeyi amaçlamaktadır. Kısaca, UCCN ile kültürel çeşitliliğin artırılması, sürdürülebilir kalkınmanın teşvik edilmesi hedeflenmekte ve küresel bir platformda şehirlerin uluslararası düzeyde görünürlüğ̈̈ ve tanıtımı desteklenmektedir. UCCN kapsamında, edebiyat, film, müzik, zanaat ve halk sanatları, tasarım, gastronomi ve medya sanatları olmak üzere yedi farklı yaratıcı alan yer almaktadır. Dünya genelinde 70'i aşkın ülkeden 246 şehir UCCN'ye kayıtlıdır. Bu çalışma, Türkiye'de bazı șehirlerin film alanı üzerinden UCCN'ye katılım potansiyelinin incelenmesini amaçlamaktadır. Nitel araştırma yöntemleriyle gerçekleştirilen çalışmada, ikincil veriler betimsel analiz aracılığıyla değerlendirilmektedir. Çalışmada öncelikle UCCN ve özellikle dünya genelinde film alanı üzerinden UCCN'ye dâhil olan şehirler hakkında bilgi verilmektedir. Ardından, Türkiye'de film turizmi konusunda öne çıkan destinasyonlar UCCN film alanı kriterleri üzerinden değerlendirilmekte ve yaratıcı şehirler ağına girme potansiyelleri incelenmektedir. Çalışma sonucunda UNESCO tarafindan belirlenen kriterlere uygunluğu nedeniyle Antalya, İzmir ve Muğla'nın UCCN'ye film alanı üzerinden dâhil olma potansiyelinin yüksek olduğu sonucuna ulaşılmıştır. Çalışma, sürdürülebilir turizm anlayışını benimsemiş destinasyonlarda yaratıcıllı̆ın bir strateji olarak uygulanabilirliğine ilişkin bulgular sunması açısından önem taşımaktadır. Böylelikle kitle turizminin turizmin ekonomik kazanımlarını önde tutan ve turist odaklı yaklaşımın yerine, turizmin sosyo-kültürel etkilerini de gözeten ve yerel halkın ve toplulukların öncelikli olduğu sürdürülebilir turizm anlayışına geçiş sürecine de katkı sağlanabilecektir.

Anahtar Kelimeler: UNESCO Yaratıcı Şehirler Ağı, Yaratıcı Turizm, Film, Turizm, Türkiye. 


\title{
Cities are on the Stage! Evaluation of Turkey in terms of UNESCO Creative Cities Network - Film Field
}

\author{
PhD Candidate Çağla Asłı Gülduran ${ }^{1}$ \\ Assoc. Prof. Dr. Ișıl Arıkan Saltık ${ }^{2 *}$
}

First received: 19.09 .2020

Accepted: 16.11 .2020

\section{Citation:}

IBAD Journal of Social Sciences

Issue: Special Issue $\quad$ Pages: 335-358

Year: 2020

This article was checked by Turnitin. Similarity Index 08 \%

${ }^{1}$ Muğla Sitkı Koçman University, Turkey, caglasli87@hotmail.com,

ORCID ID 0000-0002-3364-457X

${ }^{2}$ Muğla Sitkı Koçman Universitiy, Turkey, isilas@mu.edu.tr,

ORCID ID 0000-0002-3456-2787

* Corresponding Author

\begin{abstract}
The UNESCO Creative Cities Network (UCCN) was founded in 2004 by UNESCO as a result of a project to increase cooperation between cities, which respect creativity as an important factor in the urban development process. The main purpose of the project is to promote the development of culture and creativity against the threats of homogenization and commodification of the culture that emerged with the effect of globalization. In addition, it aims to contribute to the promotion and development of cities at the international level through its cooperation network, and to support sustainable development at both global, national and local levels. UCCN aims to increase cultural diversity and promote sustainable development, and supports to international visibility and promotion of cities on a global platform. Within the scope of UCCN, there are seven different creative fields, which are namely, literature, film, music, crafts and folk arts, design, gastronomy and media arts. Worldwide, 246 cities from over 70 countries are registered in UCCN. This study intends to investigate the potential of some cities in Turkey, in terms of participation in the creative cities network via film field. In this qualitative research, secondary data were analyzed. Firstly, a generic review about UCCN in general and the cities included in UCCN through film field in particular, is provided. Afterward, prominent film tourism destinations in Turkey are evaluated through the criteria of film field of UCCN and their potential to participate into UCCN are examined. It has been concluded that Muğla, Antalya and İzmir are the cities which have a high potential to be included in the UCCN through the film field due to its compliance with the specified criteria. The study is important in terms of providing findings regarding the potential of creativity to be implemented as a strategy in the destinations that have adopted sustainable tourism approach. Thus, it is supportive of the transition from mass tourism which prioritizes the economic gains of tourism and focus on tourists, to a sustainable tourism approach which respects the socio-cultural impacts of tourism and focus also on local people and communities.
\end{abstract}

Keywords: UCCN, Creative Cities Network, Creative Tourism, Film, Tourism, Turkey. 


\section{GİRIŞ}

Küreselleşme süreci ile tek tip kültürün ortaya çıkmasının neden olduğu kültür metalaşması karşısında, yaratıcı sanatlar ve kültürel endüstriler kavramlarının birleşimiyle yaratıcı endüstriler kavramı ortaya çıkmıştır. Yaratıcı endüstrilerin ekonomik kalkınmadaki öneminin anlaşılmasıyla konuyla ilgili yeni kavramların gelişmeye başladığı, 1990'lı yılların başlarında Avustralya'da, ortalarında da İngiltere'de konuya olan ilginin arttığı görülmektedir. Yaratıcı endüstriler kavramıyla ilintili olarak ortaya çıkan kavramlardan birisi de "Yaratıcı Şehirler" dir. Yaratıcı șehirler kavramını ilk kez kullanan Yencken (1988), kavramı vatandaşı için eşsiz deneyimler sunmak üzere kendini adamış, yaşam standardının yüksek olduğu, fiziksel ortamında geçmişinden ve kültüründen izler taşıyan şehirler olarak özetlemiştir.

Yaratıcı şehirler, 2004 yılında UNESCO tarafından, sürdürülebilir kentsel kalkınmanın başarımında kültür ve yaratıcılığın stratejik bir güç olarak tanımlanmasına dayalı olarak uluslararası düzeyde işbirliğinin sağlanmasını amaçlayan UCCN'un kurulmasıyla ön plana çıkmıştır. Yaratıcı Şehirler Ağı üyeliği, şehirlerin uluslararası tanıtımına sağladığı katkı sayesinde güçlü bir destinasyon pazarlama aracı niteliği de taşımaktadır. Ağa üye şehirler, tarihi ve kültürel değerlerini içeren yaratıcı deneyimler sunarak, kültür ve yaratıcılığın birlikteliğinde yaşanacak yeni deneyimler arayışında olan ziyaretçilere ulaşma konusunda rekabet gücü kazanabilmektedir. Ajanovic ve Çizel (2015) tarafindan belirtildiği üzere, Yaratıcı şehirler ağı yerel halkın şehrin marka değeri konusunda farkındalığının oluşturulması ve artırılması için de firsat yaratabilmektedir.

UNESCO Yaratıcı Şehirler Ağı kapsamında, üye olacak şehirlerin tarihine ve dinamizmine uygun olarak seçilebilecek, edebiyat, film, müzik, zanaat ve halk sanatları, tasarım, gastronomi ve medya sanatları olmak üzere, yedi yaratıcı alan belirlenmiştir. 2020 yılı itibariyle, Dünya genelinde 70'i aşkın ülkeden 246 şehir, Türkiye'den ise altı şehir UCCN'ye üyedir. Bu çalışma, sürdürülebilir turizm anlayışını benimsemiş destinasyonlarda yaratıcılığın bir strateji olarak uygulanabilirliğine firsat sunan Yaratıcı Şehirler A ̆ğ hakkında farkındalığı artırmak ve Türkiye'de bazı şehirlerin film alanı üzerinden UCCN'ye katılım potansiyelini incelemek amacıyla gerçekleştirilmiştir. Çalışmada öncelikle UCCN ve dünya genelinde film alanı üzerinden UCCN'ye dâhil olan şehirler hakkında bilgi verilmektedir. Ardından, Türkiye'de film turizmi konusunda öne çıkan destinasyonlar UCCN film alanı kriterleri üzerinden değerlendirilmekte ve yaratıcı şehirler ağına girme potansiyelleri incelenmektedir. Bu bağlamda bu çalışma, ulusal yazında UNESCO Yaratıcı Şehirler Ağı film alanı konusunda yapılmış sınırlı sayıda araştırma olması nedeniyle önemlidir. Çalışma sonuçlarının, gelecek araştırmalarda birincil verilerin toplanmasına olanak verecek veri toplama araçlarının geliştirilmesine katkı sağlaması beklenmektedir. Çalışma aynı zamanda UNESCO Yaratıcı Şehirler Ağ ve film turizmi ilişkisini irdelemek suretiyle alanyazının gelişimine de katkı sağlamakta ve benzer çalışmalardan farklılaşmaktadır.

\section{UNESCO YARATICI ŞEHIRLER AĞI}

Küreselleşme ve bilgi teknolojilerinde yaşanan gelişme geleneksel iş alanlarında dönüşüm yaşatırken, yeni iş kollarının ortaya çıkışına ortam hazırlamıştır. Bu durum, kültür ekonomisi ve yaratıcı ekonomi olarak ifade edilen, sanat ve yaratıcıllğın ön planda olduğu bilgi teknolojileri ile bütünleşmiş yeni bir pazar ortaya çıkmasını sağlamıştır (Aslan, 2017). Kültür ve yaratıcı endüstrilerin ortaya çıkışı ile katma değer kazanımının hızlanması, istihdamın artışı bu konuya daha fazla ilgi gösterilmesine neden olmuştur (Işıkman, 2017). 18. yy'da fikir olarak ortaya çıkan yaratıcı sanatlar ve kültürel endüstrilerin 1990'lı yıllarda yaratıcı endüstrileri ortaya çıkarmasıyla, kavram literatüre girmiştir (Hartley 2005'den aktaran Hocaoğlu, 2015). 1961 yılından itibaren, yaratıcı endüstrilere kentsel ekonomik büyüme için önem verilmeye başlanmıştır (Lee ve Pose, 2014). 1997 yılında İngiltere Kültür Medya ve Spor Müdürlüğü (Department for Digital, Culture, Media and Sport, 2001) tarafindan Yaratıcı Endüstriler Görev Birimi kurulmuş ve yaratıcı endüstriler reklamcılık, moda, yayıncılık, sanat ve antika pazarı, film, yazılım, mimari, eğlence yazılımı, televizyon ve radyo, el sanatları, müzik, tasarım ve performans sanatları olarak belirlenmiştir.

Yaratıcı endüstrilerin önem kazanması ile turizmin gelişim süreci ve performansı da bu dönüşümden etkilenmiştir. Turizm deneyimleri de bu değişim ile birlikte sıra dışı bir hal almıştır (Richards, 2011). Yaratıcı turizm, literatüre kültürel turizmin bir uzantısı olarak geçmektedir (Richards ve Marques, 2012). UNESCO (2006) tarafından yaratıcı turizm, "bir bölgenin sanatını, kültürel mirasını ya da özgün 
karakterini katılımcı öğrenimle deneyimlemek amacıyla, etkileşimli ve özgün deneyimler edinmeye yönelik gerçekleştirilen ve bu bölgenin yaşayan kültürünün yaratıcısı yerel halkla iletişimi sağlayan seyahatler” olarak tanımlanmaktadır. Bir başka tanımla yaratıcı turizm, ziyaretçilere gerçekleştirildikleri tatil yerinin karakteristik özelliklerini içeren kurslara aktif katılım ve öğrenme deneyimleri yoluyla yaratıcı potansiyellerini geliştirme firsatı sunan turizm çeşidi olarak ifade edilmektedir (Richards ve Raymond, 2000).

Küreselleşmenin etkisiyle turizm pazarında artan şehirlerarası rekabet, şehirleri daha yaratıcı olmaya zorlamıştır. Turizm ve yaratıcılığ 1 entegre etmek için, turistik ürün ve deneyimleri geliştirmek, mevcut ürünleri canlandırmak, kültür ve yaratıcılığı öne çıkarmak, yaratıcılığı geliştirmek için ekonomik yan ürünler kullanmak, turizm deneyimine yaratıcı teknikler sunmak, şehirlere hareketlilik ve atmosfer kazandırmak gibi yollar izlenmektedir (Richards, 2014). Yaratıcı ve kültürel endüstrilerin turizm sektörü ve ekonomik gelişimi arasındaki ilişki (Della Lucia ve Segre, 2017), yaratıcı endüstriler, kültür ve turizm arasındaki ilişki (Durmaz, Platt ve Yiğitcanlar, 2010) yaratıcı şehirlerin bölgesel kalkınma üzerindeki rolü (Nižić, Rudan ve Trinajstić, 2019; Comunian, 2011), kültürel değerler aracıllğıyla yaratıcı şehirler ve kentsel kalkınmanın rekabet gücü kazanımında etkilerini (Popescu ve Corboş, 2012) ve yaratıcı şehirlerin ekonomik gelişimine yönelik (Hall, 2000) çalışmalar yaratıcı ve kültürel endüstrilerin şehirlerin bölgesel kalkınma ve ekonomik gelişim üzerindeki olumlu etkilerini göstermektedir. Son on yılda, şehirlerin kültürel ve yaratıcı endüstrileri yerel kalkınma için oldukça önem kazanmıştır. Şehirler ekonomik kalkınmayı sağlamak, daha geniş bir çevrede görünürlüğü artırmak, özellikle de turizm sektöründe bir sinerji yakalamak için yaratıcı endüstrileri bir araç olarak kullanmaktadır (Nižić, Rudan ve Trinajstić, 2019).

Kentsel miras, şehirlerin kimliğini artırmada ve sosyal ve ekonomik kalkınma için bir ortam hazırlama konusunda oldukça önemli bir yere sahiptir. Kentsel değer ve imajın geliştirilmesi için kültürel endüstriler kilit bir rol oynamaktadır. Kültür, doğrudan gelir üretimi ve istihdama olan katkısı ile yoksulluğun azaltılmasında etkin bir araç olarak kullanılmaktadır. Öyle ki günümüzde, müzeler, sergi ve tiyatrolar gibi sanatsal ve kültürel alanlar ve etkinlikler önemli gelirler sağlamakta ve yatırım firsatları sunmaktadır. Sanatsal yaratıcılık ve kültürel zenginlikler bir şehrin vatandaşları ve ziyaretçileri için mıknatıs görevi görmektedir. Özellikle gelişmekte olan ekonomiler için kültürel hizmet ve ürünlere olan talebin artışı ile ekonomi için önemi giderek fark edilir ve vazgeçilmez bir hal almaktadır. Bu durum yaratıcı ekonomi potansiyelinin artmasını da desteklemektedir (UNESCO, 2016).

"Yaratıcı Şehirler" kavramı ilk olarak Avustralyalı iş adamı ve akademisyen olan David Yencken tarafindan 1988 yılında Meanjin isimli bir dergide yayınlanan makale ile ortaya çıkmıştır. Yencken (2013), Jane Jacobs'un Şehirlerin Ekonomisi isimli kitabında şehirlerin sanayi ve ekonomik faaliyetler gibi sınırlı faktörlere oldukça bağımlı bir hal aldığı ifadesine vurgu yapmaktadır. Yaratıcılık için temel ilkenin, şehirlerdeki karmaşıklı̆̆ 1 ve çeşitliliği teşvik etmek olduğunu ileri sürmektedir. Yencken'e (2013) göre, şehirlerin kendi karmaşası içinde okunabilir, şeffaf ve anlaşılabilir bir düzeni olmalıdır. Bu bağlamda, yaratıcı bir şehirde sunulanlar yine şehrin insanlarının deneyimleri ile ilgili olmalı, fiziksel ortam kültürel geçmişten izler taşımalıdır. Genel anlamda, yaratıcı bir şehrin vatandaşlarına eşsiz firsatlar sunan ve güzel bir hayat yaşatabilen bir şehir olmasına yönelik bir anlayışın benimsenmesinin gerekliliği ifade edilmektedir.

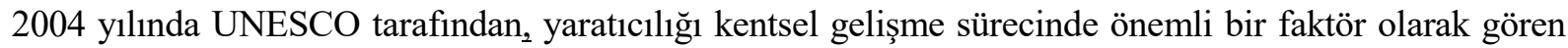
şehirlerarasındaki işbirliğini artırmak için bir proje tasarlandı. Yerel anlamda hali hazırda günlük olarak devam eden kültür ve yaratıcılık, bu işbirlikçi program ile kültürel endüstrileri teşvik ederek, yaratıcılığı, vatandaşı ve kültürel katılımını özel sektör, kamu ve diğer sivil toplum kuruluşları ile iş birliği içinde yerel halkın ihtiyaçlarına uygun olarak sürdürülebilir bir kentsel kalkınmayı desteklemek amacıyla uluslararası işbirliği ile küresel düzeyde ulaşılabilir "UNESCO Yaratıcı Şehirler Ağı” oluşturulmuştur.

UNESCO Yaratıcı Şehirler Ağı kültürel, ekonomik ve çevresel sürdürülebilir kentsel kalkınma için tasarlanmış işbirlikçi ve uluslararası bir proje olarak tanımlanmaktadır. Temel amaçları arasında, yaratıcılığın ve yaratıcı profesyonellerin gelişmesini sağlamak, üye şehirleri kentsel gelişmede yaratıc1lı̆ın önemini benimsemeleri için teşvik etmek, sürdürülebilir kalkınma için yaratıcılık ve kültür temelli bir yaklaşım ile uluslararası işbirliği sağlamak, şehirlerdeki dezavantajlı grupların kültürel yaşama katılımını ve kolay erişimini sağlamak, kültürel faaliyetlerin yaygınlaştırılması için faaliyetleri

IBAD Sosyal Bilimler Dergisi / IBAD Journal of Social Sciences, (Özel Sayı/Special Issue), 2020 
güçlendirmek yer almaktadır. Aynı zamanda kültürlerarası iletişimi ve diyaloğu güçlendirmek, sosyal uyum ve çeşitliliği sağlamak ve vatandaşın refahını desteklemek de UCCN'nin amaçları arasındadır (en.unesco.org). Özetle, Yaratıcı Şehirler Ağı, yerelden küresele doğru giden işbirliği ağı içinde yaratıcılığı ve kültürel endüstrileri sürdürülebilir kalkınmanın önemli anahtarı konumunda gören ve üye olan şehirlere kentsel kalkınma için fırsat yaratan bir ağ olarak tanımlamak mümkündür. Sürdürülebilir kalkınmanın çevresel, sosyo-kültürel ve ekonomik boyutlarını desteklemektedir.

UNESCO, 2005 yılında Kültürel Çeşitliliğin Korunması ve Geliştirilmesi Toplantısı'nda imzalanan Kültür Sözleşmesi ile kültür ve yaratıcılığın kentsel kalkınmadaki önemini vizyonuna dahil etmiştir. Yaratıcı Şehirler Ağı'nın kuruluşundan sonra, üye şehirlerin izlediği politikalar ve faaliyetler ile kültür ve yaratıcılığın yerel ekonomilerdeki önemi kanıtlanmıştır. 2015 yılının Eylül ayında 193 ülkenin işbirliği ile, 'Dünyamızı dönüştürmek için 17 Hedef' sloganı ile, 17 Sürdürülebilir Kalkınma Hedefi ve 169 hedef belirlenmiştir. Belirlenen hedefler, UNESCO ve diğer paydaşların uluslararası kalkınma gündeminin kültür ve yaratıcılık ile bütünleşmesi gerekliliğgini savunusunun göstergesi niteliğindedir. $\mathrm{Bu}$ husus, özellikle 11. hedef olan " kentleri kapsayıcı, güvenli, dayanıklı ve sürdürülebilir kılmak" hedefinde açıkça görülmektedir.

UNESCO'nun 2016 Östersund Y1llık Toplantısı'nda UCCN üyesi şehirlerin talebi doğrultusunda 20172021 yılları için dört yıllık stratejik bir rapor hazırlamıştır. Raporda, UNESCO Yaratıcı Şehirler Ağı, barış ve sürdürülebilir kalkınma kültürüne uygun olarak tasarlanmış ve yönetişim mekanizmaları ile yönetilen bir program olarak tanımlanmaktadır. Sürdürülebilir şehirler yaratmak UNESCO Kültür Programları ve Stratejilerinin tarihinde her zaman önemli bir strateji olarak yer almaktadır. 2016 yılında Ekvator'da düzenlenen Birleşmiş Milletler Konut ve Sürdürülebilir Kentsel Gelişme Konferansı (Habitat III)'nda, sürdürülebilir kentsel kalkınma için bakış açısı değişikliğinin gerekli olduğu kabul edilmiştir (UNESCO, 2017, s. 2-5). Bu raporda ilk kez sürdürülebilir kentsel kalkınma için kültürün önemi ortaya konulmaktadır. Bütünsel olarak kültür; kültürel miras, kültür turizmi ile yaratıcı ve kültür endüstrilerini de içine alarak değerlendirilmiş ve sürdürülebilir kalkınmanın ekonomik, çevresel ve sosyal boyutlarının hem sağlayıcısı hem de itici gücü olarak kabul edilmiştir (UNESCO, 2016, s. 18).

Uluslararası işbirliğinin yarattığı sinerji, kültür ve yaratıcılık endüstrilerinin gelişimini hızlandırmaktadır. $\mathrm{Bu}$ gelişime parelel olarak, şehirlerin üyelik başvurularının da her dönem arttı̆ğ görülmektedir. 2020 itibariyle, UCCN üyesi 246 şehir bulunmaktadır. 2030 Sürdürülebilir Kalkınma Gündemi ve Yeni Kentsel Gündem'in benimsenmesi, Yaratıcı Şehirler Ağı'’nın stratejisinin yeniden şekillenmesi için bir ortam hazırlamıştır. Kültürün sürdürülebilir kalkınmadaki önemli rolü, 2030 Sürdürülebilir Kalkınma Gündemi’nde de vurgulanmaktadır. Kısaca ifade etmek istenirse, tarihsel gelişim, kültür ve yaratıcılığın şehirler için sürdürülebilir kentsel kalkınmada önemli rol oynadığını ve UNESCO tarafından vizyon olarak kabul edildiğini göstermektedir.

Uluslararası düzeyde yaratıcı endüstrilere gösterilen ilginin ve yönelimin artmasıyla uyumlu olarak, ulusal düzeyde de yaratıcı endüstrilere daha fazla önem verilmeye başladığı görülmektedir. 11. Kalkınma Planı (2019) incelendiğinde telif haklarına konu olan kültürel endüstrilere ilişkin ifadeler dikkat çekmektedir. "Telif haklarına konu olan kültür endüstrilerinin; mevcut kayıt, veri ve ulusal istatistiklerinin çeşitlendirilmesi (455.1), ekonomik boyutuna ilişkin ölçüm raporu hazırlanması (455.2), ... kültür endüstrilerine yönelik projelerin, ... UNESCO Kültürel İfadelerin Çeşitliliğinin Korunması ve Geliştirilmesi Sözleşmesi de gözetilerek desteklenmesi (457.4), ... özel destek programlarının geliştirilmesi (458.5), kültür endüstrileri ve kültürel girişimlere yönelik mevcut desteklerin etki analizinin yapılarak, ... destek mekanizmalarının geliştirilmesi (637), " kültürel endüstrilerin geliştirilmesine yönelik olarak 11. Kalkınma Planı'nda yer alan ifadelerdendir. Yaratıcı endüstrilerden film alanı odağa alınarak yapılan incelemede ise, "Kültürümüzün temel unsurlarının, tarihimizin önemli şahsiyetlerinin, olaylarının ... tiyatro, sinema, belgesel, dizi ve çizgi filmlerle anlatılması (630.7), Türk sinemasının dünyada tanınan bir marka haline gelmesi için sinema endüstrisinin gelişimi sağlanarak uluslararası rekabet gücünün artırılması (639), bu kapsamda Ulusal Sinema Müzesi ve Arşivi'nin kurulması (639.1), ... ülkemizde çekimi yapılacak yabancı yapımların desteklenmesi (639.2), sinema yapım, dağıtım ve gösterim faaliyetlerinde tekelleşmenin önüne geçmeye yönelik düzenlemeler yapılarak, ... yapıların sinema statüsüyle kullanımının teşvik edilmesi (639.3) ifadelerinde konuya verilen önem açıkça görülmektedir. Benzer şekilde, Çevre ve Şehircilik Bakanlığı (2019, s, 352) 
tarafindan hazırlanan 2020-2023 Ulusal Akıllı Şehirler Stratejisi ve Eylem Planı'nda yaratıcı endüstrilerin hedefler arasında belirtildiği dikkat çekmektedir. Eylem Planı'nda yer alan Yaşanabilir Mekanlar ve Sürdürülebilir Şehirler yaratmak için Aklll Şehirler Stratejisi Hedefleri içinde "kültür ekonomisi bileşenlerini içeren ve yaratıcı endüstriler alanının geliştirilebileceği ortamlar olması" ifadesi, Ulusal Akıllı Şehirler Stratejisi'nde yaratıcı endüstrilere verilen önemin bir göstergesi niteliğindedir.

Şehirlere yaratıcılık katmak ve sürdürülebilir kalkınmanın sosyo-kültürel, çevresel ve ekonomik boyutlarını desteklemek için oluşturulan UNESCO Yaratıcı Şehirler Ağı'nda yedi yaratıcı alan bulunmaktadır. Şehirler, gastronomi, müzik, zanaat ve halk sanatları, medya sanatları, tasarım, film ve edebiyat alanlarından kendi altyapılarına uygun olan bir alana başvurabilmektedir. Başvuruları kabul edilen şehirler, başvurdukları alanda yaratıcı şehir unvanını kazanmaktadır. UNESCO Yaratıcı Şehirler Ağı Başvuru süreci Şekil 1'de özet olarak sunulmaktadır.

Şekil 1. UNESCO Yaratıcı Şehirler Ă̆g Başvuru Süreci

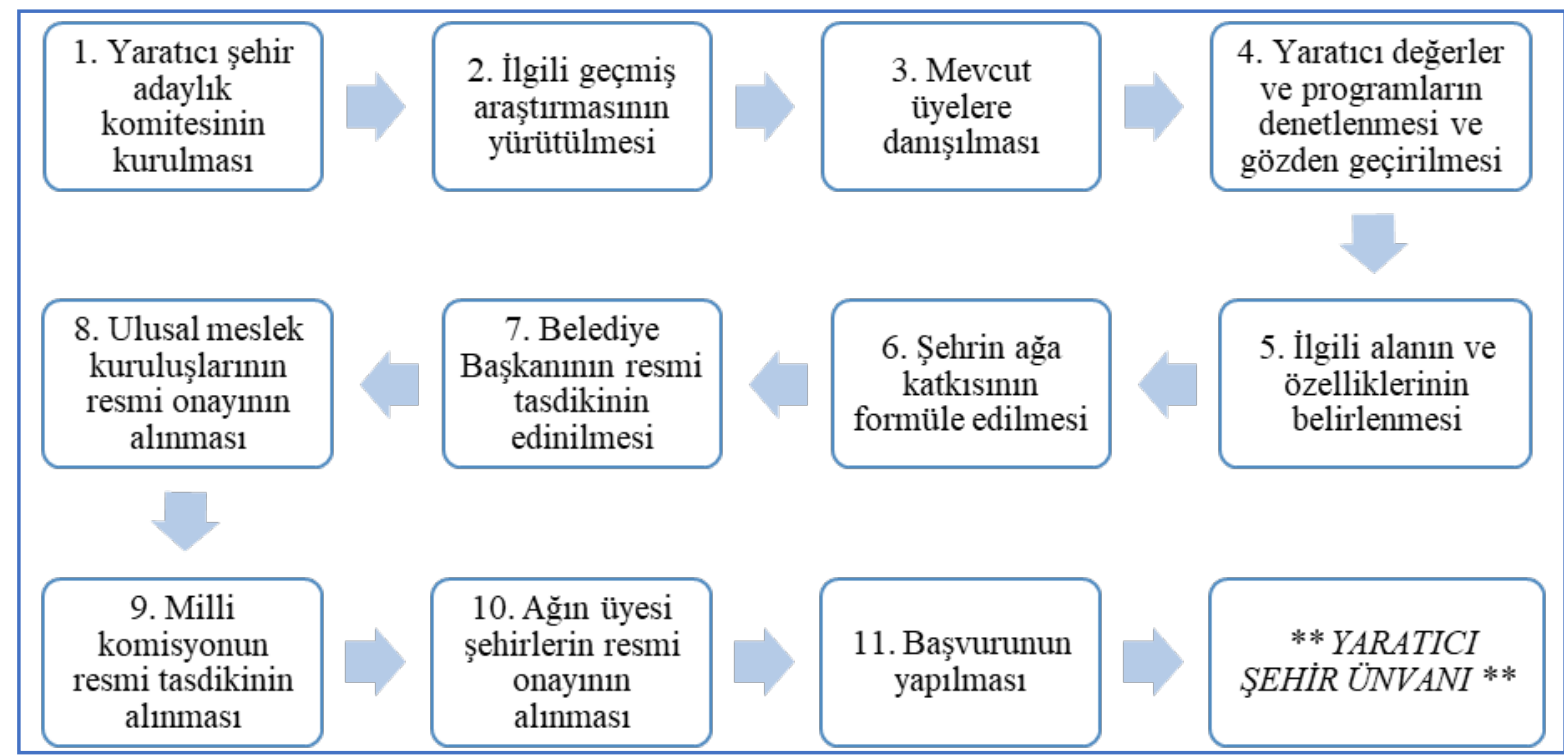

Kaynak: UNESCO Yaratıcı Şehirler Ağı'ndan erişilen bilgilere dayalı olarak yazarlar tarafından hazırlanmıştır.

Şekil 1'de görüldüğü üzere; UNESCO Yaratıcı Şehirler Ağı'na katılmak isteyen şehirler öncelikle Yaratıcı Şehir adaylık komitesini kurarak, şehrin geçmişine ilişkin bir araşstırma yürütmektedir. Araştırma sonuçları 1şığında, mevcut üyelere danışılarak, şehrin sahip olduğu yaratıcı değerler ve programlar denetlenmekte ve gözden geçirilerek şehir için uygun olan yaratıcı alan ve özellikleri belirlenmektedir. Belirlenen alanda şehrin UNESCO Yaratıc1 Şehirler A ̆ğ’na sağlayacağı katkının içeriği oluşturularak, sırasıyla şehrin belediye başkanının, ulusal meslek kuruluşlarının, milli komisyonun ve UCCN üyesi olan diğer şehirlerin resmi onayları alınarak başvuru süreci tamamlanmaktadır. Aday şehir, başvurusu kabul edildiği takdirde başvurduğu alanda yaratıcı şehir unvanı almaya hak kazanmaktadır. Bu kapsamlı başvuru sürecinin başarıyla tamamlanabilmesi için; katılımı zorunlu olarak tanımlanan Belediye ve meslek kuruluşlarının yanı sıra şehrin diğer paydaşlarının da dâhil olduğu, etkin yerel yönetişim ve işbirliğinin sağlandığı, gerekçeleri ve katkısı iyi tasarlanmış, çok boyutlu düşünülerek ve koordineli hareket edilerek sürecin yönetilmesi gerektiğini söylemek mümkündür.

2020 yılı itibariyle, Türkiye'den altı şehir Yaratıcı Şehirler Ağı'na üyedir. Türkiye'nin 2015-2019 yılları arasında, dört farklı alanda yaratıcı şehir ağına katılım sağlamış şehirleri olmasına karşın, henüz film, medya sanatları ve edebiyat alanlarından üye olan bir şehri bulunmamaktadır. Yaratıcı şehirler, ağa katılım alanları ve yılları ile şu şekilde sıralanmaktadır: Gaziantep (Gastronomi-2015), Hatay (Gastronomi-2017), İstanbul (Tasarım-2017), Kütahya (Zanaat ve Halk Sanatları-2017), Afyonkarahisar (Gastronomi-2019), Kırşehir (Müzik-2019) üyedir. Türkiye'deki yaratıcı şehirler, logoları, ağa katılım yılları, yaratıcı alanları ve bu kapsamda gerçekleştirdikleri çalışmalar hakkında kısa bilgi Tablo 1'de özet olarak sunulmaktadır. 
Tablo 1. Türkiye'deki Yaratıcı Şehirler

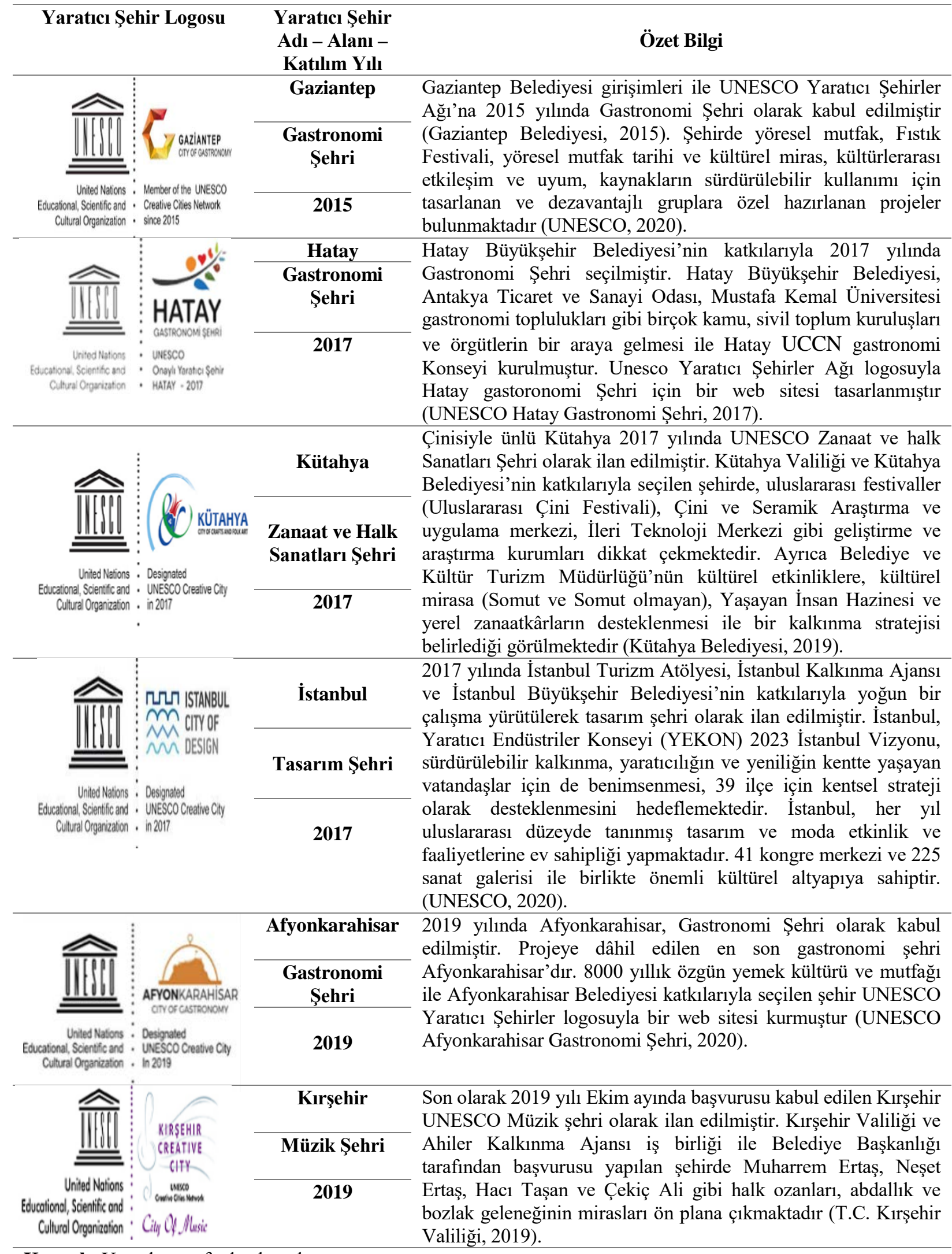

Kaynak: Yazarlar tarafindan hazırlanmıştır. 
UNESCO Yaratıcı Şehirler Ağı ile ilgili yapılmış çalışmalar incelendiğinde; gastronomi alanından ağa dahil olan şehirlerin değerlendirildiği araştırmaların daha fazla olduğu görülmektedir. Dünya genelinde somut olmayan kültürel miras ve gastronomi arasındaki ilişki kavramsal olarak değerlendirildiği (DeMiguel-Molina vd., 2016), 2018 yılı itibariyle ağa katılmış tüm gastronomi şehirlerinin gastronomi turizmi açısından incelendiği (Akdu ve Akdu, 2018), gastronomi şehri ünvanını sahip Macau (Çin) şehrinin (Yu ve Sun, 2019), Florianopolis (Brezilya) şehrinin (Emmendoerfer, Emmendoerfer ve Ashton, 2016), Georgetown (Malezya) şehrinin (Khoo ve Badarulzaman, 2014) incelendiği çalışmalar bulunmaktadır. Ayrıca ulusal yazında Türkiye'deki gastronomi şehri ünvanına sahip Gaziantep (Mutlu, 2019; Akın ve Bostanc1, 2017; Giritlioğlu, İpar ve Karakan, 2016) ve Hatay (Demirtaş ve Pektaş, 2020; Taştan ve İflazoğlu, 2018) şehirlerinin yanı sıra Kocaeli (Alyakut ve Küçükkömürler, 2019), Bitlis (Arınç, 2017) ve Mardin (Gürbüz, Serçek ve Toprak, 2017) şehirlerinin gastronomi şehri olarak Yaratıcı Şehirler Ağı'na katılma potansiyellerinin değerlendirildiği çalışmaların yapıldığı görülmektedir. Bu çalışmaların yanı sıra Şanlıurfa şehrinin müzik şehri olma potansiyelinin araştırıldığı (Yetkin, 2019), 2004-2015 y1lları arasında ağa dahil olan tüm edebiyat şehirlerinin incelendiği (Yalçın ve Turan, 2018), İzmir şehrinin tasarım şehri olma potansiyelinin incelendiği (Dereli, 2016) çalışmalar yapıllmıştır.

Yaratıcı şehirler film alanı kapsamındaki literatür incelendiğinde, yaratıcı endüstriler ve kültürel miras turizmi arasındaki ilişki üzerinden İstanbul ve Londra film endüstrilerinin karşılaştırıldığı (Durmaz, Platt ve Yiğitcanlar, 2009), Antalya şehrinin film endüstrisindeki gelişmeler doğrultusunda film şehri olma potansiyelinin incelendiği (Durmaz, Yiğitcanlar ve Velibeyoğlu, 2008; Ajanovic ve Çizel, 2015) sınırlı sayıda çalışma belirlenmiş̧ir. Filmlerin, insanlar üzerinde önceden tahmin edilmesi zor değişkenlerden etkilenerek filmde çekilen bölgeyi ziyaret etme isteği yarattığı genel olarak kabul görmektedir (Beeton, 2004). Filmler, içine yerleştirme işlemi sonrasında destinasyonların çok sayıda insana tanıtılmasında önemli bir pazarlama aracı olarak görülmektedir (Saltık, Coşar ve Kozak, 2010). İnsanların TV programları ve filmlerin çekildiği yerleri izlemelerinin etkisiyle, o yerleri gidip görme isteği ile ortaya çıkan film turizmi (Beeton, 2008), günümüzde uluslararası düzeyde önem taşıyan bir turizm çeşidi konumundadır. Bu bağlamda, yaratıcı sektörler içinde film alanından uluslararası bir platformun üyesi olmanın; film turizminin gelişimine, destinasyonun uluslararası düzeyde tanıtımına, iç turizmin hareketlendirilmesine ve dış turizmin gelişimine destek olacağını söylemek mümkündür.

Yaratıcı Şehirler Ağı, Film Alanı UNESCO tarafından belirlenmiş olan kriterler doğrultusunda uygun olan şehirlerin başvuruları UNESCO tarafından değerlendirilmektedir. Başvurular öncelikli olarak UNESCO Türkiye Milli Komisyonu tarafından düzenlenmekte ve sonrasında Uluslararas1 Ağ'a sunulmaktadır. UNESCO Yaratıcı Şehirler Ağı'na film alanından başvuru kriterleri Tablo 2'de sunulmaktadir.

Tablo 2. Unesco Yaratıcı Şehirler Ağı Film Alanı Başvuru Kriterleri

\begin{tabular}{|l|l|}
\hline \multirow{3}{*}{} & $\begin{array}{l}\text { i. Film stüdyoları, film çekimi yapılan alan ve manzaralar vb. gibi filmle ile ilgili önemli } \\
\text { altyapını bulunması }\end{array}$ \\
\cline { 2 - 2 } & $\begin{array}{l}\text { ii. Filmlerin yapımı, dağıtımı ve ticarileştirilmesine ilişkin sürekli veya kanıtlanmış bağlantıların } \\
\text { varlığı }\end{array}$ \\
\cline { 2 - 2 } & $\begin{array}{l}\text { iii. Film festivallerine, gösterimlerine ve filmle ilgili diğer etkinliklere ev sahipliği yapma } \\
\text { deneyimi }\end{array}$ \\
\cline { 2 - 2 } & iv. Yerel, bölgesel ve uluslararası düzeyde işbirliği girişimleri \\
\cline { 2 - 2 } & $\begin{array}{l}\text { v. Arşivler, müzeler, özel koleksiyonlar ve/veya film enstitüleri biçiminde film mirasına sahip } \\
\text { olması }\end{array}$ \\
\cline { 2 - 2 } & vi. Film/sinema okulları ve eğitim merkezleri \\
\cline { 2 - 3 } & vii. Yöresel veya ulusal film yapımını ve/veya yönetimini yaygınlaştırma çabası \\
\cline { 2 - 3 } & viii.Yabancı filmler hakkında bilgi paylaşımını teşvik eden çalışmalar \\
\hline
\end{tabular}

Kaynak: Unesco (2014, s. 2)

Tüm dünyada film alanı üzerinden başvurusu kabul edilen 2019 itibariyle 18 şehir bulunmaktadır (UCCN, Cities of Film, 2020). Şekil 3 'te Unesco Yaratıcı Şehirler Ağg'na dahil olan tüm film şehirleri dünya haritası üzerinde gösterilmektedir (UCCN Busan City of Film, 2020). 
Şekil 2. Dünya Genelinde UNESCO Yaratıcı Şehirler Ağı Film Şehirleri

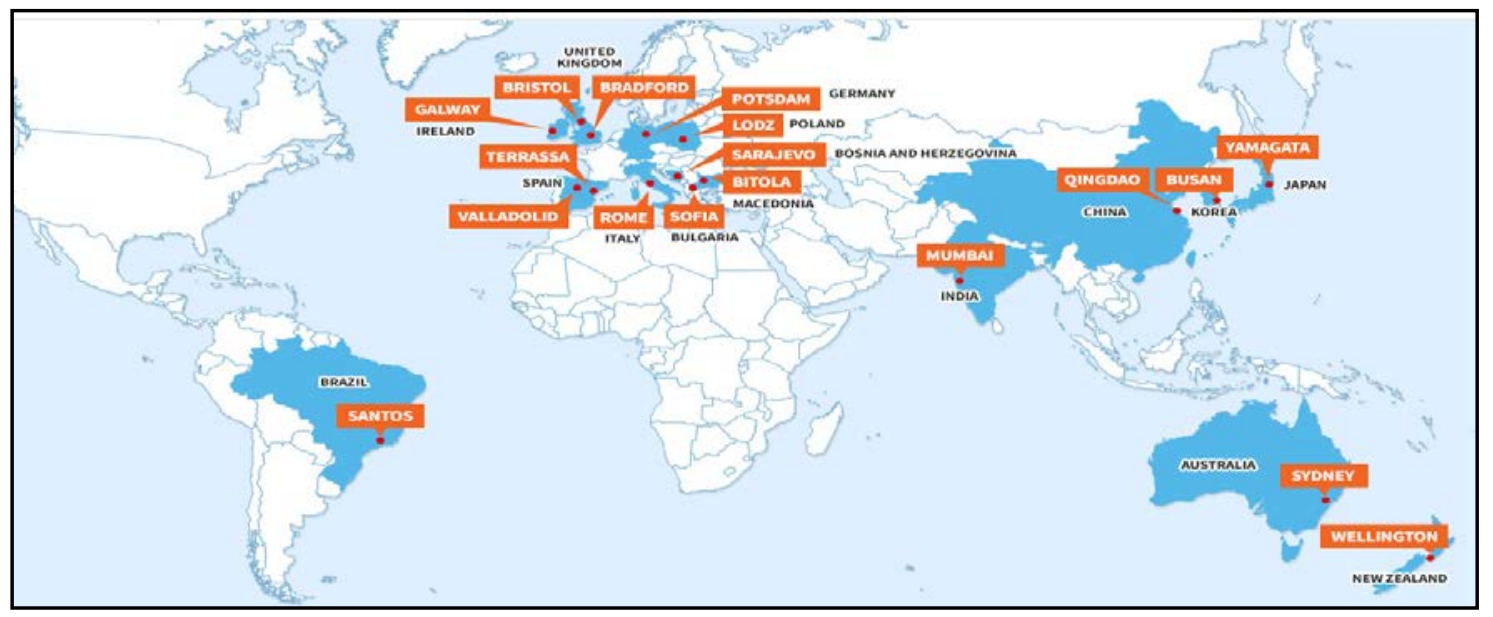

Şekil 2'de yer alan Bradford (Birleşik Krallık - 2009), Sidney (Avustralya - 2010), Galway (İrlanda 2014), Sofya (Bulgaristan - 2014), Busan (Güney Kore - 2014) Santos (Brezilya - 2015), Roma (İtalya 2015), Bitola (Makedonya - 2015), Lodz (Polonya - 2017), Qingdao (Çin - 2017), Bristol (Birleşik Krallık - 2017), Terrassa (İspanya - 2017), Sarajevo (Bosna Hersek - 2019), Postdam (Almanya - 2019), Yamagata (Japonya - 2017), Wellington (Yeni Zelanda - 2019), Valladolid (İspanya - 2019), Mumbai (Hindistan - 2019) şehirleri, Film Şehri olarak UNESCO Yaratıcı Şehirler Ağı'na kabul edilmiştir. Tablo 3 'te UNESCO Yaratıcı Şehirler A ğı'nda yer alan film şehirleri hakkında bilgi yer almaktadır.

Tablo 3. UNESCO Yaratıcı Şehirler Ă̆g Film Şehirleri

\begin{tabular}{|c|c|c|c|c|}
\hline Şehir & Yil & $\begin{array}{c}\text { Film } \\
\text { Komisyonu }\end{array}$ & $\begin{array}{l}\text { Web } \\
\text { Sitesi }\end{array}$ & Film Şehrinin Özellikleri \\
\hline $\begin{array}{l}\text { Bradford } \\
\text { (Birleşik } \\
\text { Krallık) }\end{array}$ & 2009 & Var & Var & $\begin{array}{l}10 \text { yılı aşkın süredir Film Şehri unvanına sahip olan Bradford, her } \\
\text { sene düzenli olarak film festivalleri düzenlemektedir. İlkokul film } \\
\text { sinema eğitimlerinin yanı sıra Bradford Üniversitesi'nde doktora } \\
\text { düzeyi dâhil olmak üzere, film ile ilgili } 45 \text { farklı bölümde } \\
\text { eğitimler vermektedir. }\end{array}$ \\
\hline $\begin{array}{l}\text { Sidney } \\
\text { (Avustralya) }\end{array}$ & 2010 & Var & Var & $\begin{array}{l}\text { Sydney, Avustralya için sinema merkezi olarak kabul } \\
\text { edilmektedir. Ülkede tüm insanların yaklaşık } \% 60 \text { '1 burada } \\
\text { bulunan prodüksiyon ve post prodüksiyon işlerinde istihdam } \\
\text { edilmektedir. }\end{array}$ \\
\hline $\begin{array}{l}\text { Busan } \\
\text { (Güney Kore) }\end{array}$ & 2014 & Var & Var & $\begin{array}{l}\text { Güney Kore'de film çekimi yapılan ilk şehirdir. TV } \\
\text { programlarında ilgi çekici bir yer olarak değerlendirilen Busan } \\
\text { aynı zamanda doğal güzellikleri ile de dikkat çekmektedir. Asya } \\
\text { için film ve görsel endüstrisinde hayati önem taşıyan yaratıcı } \\
\text { merkez haline gelmiştir. Busan'da sloganı "Herkes için Film" } \\
\text { olan bir sinema merkezi bulunmaktadır. Ayrıca Asya'nın önde } \\
\text { gelen festivalleri arasında yer alan Busan Uluslararası Film } \\
\text { Festivali (BIFF), 1996 yılından bu yana Busan'da } \\
\text { gerçekleştirilmektedir. }\end{array}$ \\
\hline $\begin{array}{l}\text { Galway } \\
\text { (İrlanda) }\end{array}$ & 2014 & Var & Var & $\begin{array}{l}\text { Tarihi ve mimarisi ile öne çıkan Galway'in, doğal çekicilikleri } \\
\text { senarist ve yazarların dikkatini çekmiştir. Şehirde Sanat Evi } \\
\text { Sineması kurulmasının yanı sıra, film çekimleri ve film } \\
\text { festivalleri desteklenmektedir. }\end{array}$ \\
\hline $\begin{array}{l}\text { Sofya } \\
\text { (Bulgaristan) }\end{array}$ & 2014 & Var & Yok & $\begin{array}{l}\text { Bulgaristan'ın en büyük sinema okulu olan NAFTA Sofya'dadır. } \\
18 \text { yıldır devam eden Sofya Film Festivali Balkanlar'ın en büyük } \\
\text { ve önemli film festivalidir. Özellikle gençler için istihdam } \\
\text { yaratılması konusunda hassas davranılmaktadır. }\end{array}$ \\
\hline $\begin{array}{l}\text { Santos } \\
\text { (Brezilya) }\end{array}$ & 2015 & Var & Var & $\begin{array}{l}\text { 1900'lere kadar uzanan film mirasına sahiptir. Santos Film } \\
\text { Komisyonu liderliğinde son } 5 \text { yılda } 300 \text { çekim yapılmış ve } 2.3 \\
\text { milyon ABD Doları katma değer sağlanmıştır. Toplum Sineması } \\
\text { etkinlikleri ve haftalık açı hava sineması etkinlikleri }\end{array}$ \\
\hline
\end{tabular}




\begin{tabular}{|c|c|c|c|c|}
\hline Şehir & Yll & $\begin{array}{c}\text { Film } \\
\text { Komisyonu }\end{array}$ & $\begin{array}{l}\text { Web } \\
\text { Sitesi }\end{array}$ & Film Şehrinin Özellikleri \\
\hline
\end{tabular}

düzenlenmektedir. Cine Escola projesi ile alanda gençlere özel istihdam imkânı yaratılmaktadır.

\begin{tabular}{|c|c|c|c|c|}
\hline $\begin{array}{l}\text { Roma } \\
\text { (İtalya) }\end{array}$ & 2015 & Var & Var & $\begin{array}{l}\text { 20. yy başlarına kadar uzanan film tarihi ve mirasına sahip olan } \\
\text { Roma'da Cinecitta (Şehir sinemaları) Stüdyoları bulunmaktadır. } \\
\text { 2006'dan bu yana düzenlenen Uluslararası Roma Film Festivali, }\end{array}$ \\
\hline
\end{tabular}
dünyanın en iyi film festivalleri arasında kabul görmektedir. EMotion Rome projesi ile edebiyat, film ve sinemada yolu kesişenler için kültürlerarası çeşitliliği ve diyaloğu güçlendirmektedir. Uluslararası Film Koruma Okulu ile öğrenci değişim programı bulunmaktadır.

Bitola 2015 Bilgi yok Yok Şehrin film mirası 20. yy’a kadar uzanmaktadır. Manaki (Makedonya) Kardeşler Uluslararası Görüntü Yönetmenleri Film Festivali ile ünlüdür. Manaki Kardeşler Osmanlı Balkanları'nda çekilen ilk filmle ülkede tanınmaktadır.

Lodz 2017 Var $\quad$ Var 1948 yilında Ulusal Film Okulu kurulmuştur. Polonya için film
(Polonya) merkezi haline gelmiştir. Lodz Üniversitesi’nde Film Tarihi ve Teorileri Bölümü oluşturulmuştur. Film müzesi ve film festivalleri ile dikkat çekmektedir.

Qingdao (Çin) 2017 Var $\quad$ Var Çin sinemasının evi olarak tanımlanmaktadır. 1900’lü yıllara kadar uzanan film mirası bulunmaktadır. Quingdao yaratıcı endüstrilerdeki payı 2016 yılında \%14,8 artışla 8.1 milyar ABD Doları'na ulaşmıştır. Su altı stüdyosu dahil olmak üzere 10.000 $\mathrm{m}^{2}$ 'lik alanda 30 adet stüdyo bulunmaktadır.

\begin{tabular}{llll}
\hline $\begin{array}{l}\text { Bristol } \\
\text { (Birleşik }\end{array}$ & 2017 & Var & Var \\
Krallık) & & &
\end{tabular}

Terrassa 2017 Var Var İspanya'nın film alanında öncü şehirlerinden biridir. 1887 yılında
(İspanya) ～ilk film gösterimi yapılmıştır. Şehirde, 100 yıllık bölgesel sinema Birleşik Krallık’n en büyük 10 şehri arasında olan Bristol, sinema için önemli bir merkez haline gelmiştir. 11 yıldır devam eden film festivalleri ve dünyaca ünlü filmleri ile dikkat çekmektedir. İstihdama ve sinema eğitimine katkı sağlamaktadır. tarihini içerisinde barındıran Katalonya Film Arşivi, Kütüphane ve Sinema Kompleksi bulunmaktadır.

Yamagata 2017 Var $\quad$ Var $\quad$ Yamagata'da 1989'dan bu yana düzenlenen Uluslararası Belgesel (Japonya) Film Festivali, Asya'daki ilk belgesel film festivali olarak bilinmektedir. Vatandaşlar için Film Okulu bulunmaktadır. Film alanında yaratıcı endüstriler ile istihdam desteklenmekte ve uluslararası konferanslara ev sahipliği yapmaktadır.

\begin{tabular}{|c|c|c|c|c|}
\hline $\begin{array}{l}\text { Sarajevo } \\
\text { (Bosna- } \\
\text { Hersek) }\end{array}$ & 2019 & Bilgi yok & Var & $\begin{array}{l}\text { Ülkede, sinema film ve festivallerinin merkezi haline gelmiştir. } \\
\text { Sarajevo Film Festival her sene düzenli olarak yapılmaktadır. } \\
\text { Çok sayıda ulusal ve uluslararası festivallere ev sahipliği } \\
\text { yapmaktadır. Ayrıca Sarajevo Sinema Okulu bulunmaktadır. }\end{array}$ \\
\hline $\begin{array}{l}\text { Postdam } \\
\text { (Almanya) }\end{array}$ & 2019 & Bilgi yok & Var & $\begin{array}{l}\text { Birçok filmin çekildiği Postdam'da öne çıkan önemli unsurlardan } \\
\text { birisi Filmpark’tır. Çekilen filmler ile renklendirilmiş parkta 3D } \\
\text { vb. çeşitli sinematografik eğlence faaliyetleri de yapılmaktadır. } \\
\text { Bölgenin en büyük film festivali Postdam'da } \\
\text { gerceklestirilmektedir. }\end{array}$ \\
\hline
\end{tabular}

\begin{tabular}{|c|c|c|c|c|}
\hline $\begin{array}{l}\text { Valladolid } \\
\text { (İspanya) }\end{array}$ & 2019 & Bilgi yok & Var & $\begin{array}{lcccc}60 \text { yılı aşkın } & \text { süredir } & \text { sinema } & \text { ve film faaliyetlerinin } \\
\text { gerçekleştirildiği } & \text { şehirde } & \text { çok } & \text { sayıda film } & \text { festivali } \\
\text { düzenlenmektedir. Valladolid Film Ofisi bulunmaktadır. }\end{array}$ \\
\hline $\begin{array}{l}\text { Wellington } \\
\text { (Yeni } \\
\text { Zelanda) }\end{array}$ & 2019 & Bilgi yok & Yok & $\begin{array}{l}\text { Wellington için film sektörü kültürel kimliğin bir parçası haline } \\
\text { gelmiştir. Dünyaca ünlü ve önemli çok sayıda filmin çekimine ev } \\
\text { sahipliği yapmıştır. Çok sayıda film festivali düzenli olarak } \\
\text { yapılmaktadır. }\end{array}$ \\
\hline $\begin{array}{l}\text { Mumbai } \\
\text { (Hindistan) }\end{array}$ & 2019 & Bilgi yok & Var & $\begin{array}{l}\text { Mumbai, Hindistan için film çekimlerinin yapıldı̆̆ ve tüm dünya } \\
\text { tarafından "Bollywood" olarak bilinen önemli bir destinasyondur. } \\
\text { Geniş film platoları ile öne çıkmakta ve çok sayıda turist } \\
\text { çekmektedir. }\end{array}$ \\
\hline
\end{tabular}

Kaynak: UNESCO Yaratıcı Şehirler Ağı'ndan erişilen bilgilere dayalı olarak yazarlar tarafından hazırlanmıştır. 
Tablo 3'te sunulduğu üzere 2009-2019 y1lları arasında ağa katılmış, 16 farklı ülkeden 18 şehir yer almaktadır. Birleşik Krallık ve İspanya, 2 farklı yaratıcı film şehrine sahipken, Almanya, Avusturalya, Bosna Hersek, Bulgaristan, Brezilya, Çin, Hindistan, İrlanda, İtalya, Japonya Kore, Makedonya, Polonya, ve Yeni Zelanda birer şehir yaratıı film şehri unvanını taşımaktadır. Film alanından Yaratıcı Şehirler Ağı'na dahil olan şehirler başvuru kriterleri kapsamında incelendiğinde, film şehirlerinin genel olarak (i) film ile ilgili altyapı, stüdyolar, film çekimi yapılan alan ve manzaralar vb.'nin bulunması, (ii) filmlerin yapımı, dağıtımı ve ticarileşmesi sürekli ve kanıtlanmış bağlantıların olması ve (iii) sinema ile ilgili festivallere, gösterimlere ve çeşitli etkinliklere ev sahipliği yapma deneyimine sahip olunması kriterlerini karşıladığı görülmektedir. 12 Film Şehri’nde film komisyonunun varlığı belirlenirken, 6 tanesinde bu konuyla ilgili bilgiye ulaşılamamıştır. Yalnızca 15 tanesinin web sayfasına ulaşılmıştır. Diğer şehirler için özel olarak tasarlanmış bir web sayfasına rastlanmamıştır. İlk yaratıcı film şehri ünvanının 2009'da Bradford şehrine verildiği, hemen ardından 2010'da Sidney'in film alanından yaratıcı şehirler ağına dahil olduğu, bununla birlikte 2011-2013 yılları arasında hiçbir şehrin Yaratıcı Film Şehri Ağı'na katılmadığı anlaşılmaktadır. 2014 ve 2015 yıllarında üçer adet, 2017 ve 2019 y1llarında ise beşer adet olmak üzere son altı yılda 16 yeni şehrin Yaratıcı Film Şehri unvanı aldığı görülmektedir. Yaratıcı Film Şehri unvanı alan şehirlerin son yıllarda gösterdiği dikkat çekici artışı, konuya verilen önemin bir göstergesi olarak nitelendirmek mümkündür.

\section{YÖNTEM}

$\mathrm{Bu}$ çalışma, Türkiye'de bazı şehirlerin film alanı üzerinden UCCN'ye katılım potansiyelinin incelenmesini amaçlamaktadır. Çalışmada, Türkiye'de film turizmi konusunda öne çıkan destinasyonlar UCCN film alanı kriterleri üzerinden değerlendirilmekte ve yaratıcı şehirler ağına girme potansiyelleri incelenmektedir. Araştırmada, Türkiye'de film ve dizi çekiminin yoğun bir şekilde gerçekleştirildiği belirtilen ve ünlü film çekim yerleri olarak nitelendirilen şehirler incelenmiştir. Bu kapsamda, belirtilen şehirlerin araştırma evreni olarak belirlenmesinde, Unesco Yaratıcı Şehirler Ağ Film Alanı Başvuru Kriterlerinin (i) Film ile ilgili altyapı, stüdyolar, film çekimi yapılan alan ve manzaralar vb. Olması ve (ii) Filmlerin yapımı, dağıtımı ve ticarileşmesi sürekli ve kanıtlanmış bağlantıların varlığı kriterlerini kısmen veya büyük oranda karşılamaları temel oluşturmaktadır. Türkiye'de önemli film ve dizilerin çekildiği şehirler olarak belirtilen (FilmingInTurkey, 2020); Aksaray, Antalya, Artvin, Burdur, Bursa, Nevşehir, Gaziantep, İstanbul, İzmir, Karabük (Safranbolu), Konya, Mardin, Muğla, Rize, Şanlıurfa ve Trabzon şehirleri araştırmanın evrenini oluşturmaktadır. Bu listede yer almalarına karşın, hali hazırda UNESCO Yaratıcı Şehirler Ağı'na üye oldukları ve tek bir alan üzerinden başvuru yapılabildiği için Gaziantep ve İstanbul araştırma evrenine dâhil edilmemiştir. Akdu ve Akın (2016) çalışmalarında, film ve dizilerin etkisiyle en fazla ziyaret edilen şehirlerin Muğla, Nevşehir, İstanbul, Rize, Artvin olduğunu açığa çıkarmıştır. Çalışma sonucunda belirlenen şehirlerin, bu araştırmada incelenen şehirlerle büyük oranda örtüşmesini, araştırma konusunun öneminin ve araştırma alanının uygunluğunun göstergesi olarak nitelendirmek mümkündür.

Araştırmada nitel araştırma yöntemleri kullanılmıştır. Nitel araştırmalar, "öznel olmanın olumsuz bir araştırma davranışı olmadığını, tersine bu öznelliğin gerektirdiği sorumluluğu önceden kabul ederek, açık biçimde araştırma bulgularının ortaya konmasının önemli ve gerekli olduğunu savunur" (Yıldırım ve Şimşek, 2016: s. 44). Bu çalışmada da nitel araştırma yürütüyor olmanın ayırdında olarak araştırma yürütülmüş ve araştırma bulguları açıkça sunulmuştur. Doküman incelemesi yapılarak ikincil veri kaynaklarından elde edilen veriler yorumlanarak özet halinde sunulmuştur. Doküman incelemesi, araştırma konusu ile ilgili geçmişteki olay ve olguların yer aldığı yazıll, görsel, işitsel materyallerin yanı sıra kurumsal bilgi ve belgelerin analizini ifade etmektedir (Şahin ve Gürbüz, 2018). Döküman incelemesi büyük örnekleme ulaşılması, bireysellik ve özgünlük olanağı sunması, zamandan tasarruf sağlaması, tepkiselliği barındırmaması, daha düşük maliyetlerle gerçekleştirilebilmesi gibi güçlü yanların yanı sıra, standardize edilmiş bir biçiminin olmaması, olası yanlılık ihtimalinin bulunması, yalnızca aktarılan verilerin değerlendirilebilmesi gibi zayıf yanlara da sahiptir (Bailey, 1982'den akt. Yıldırım ve Şimşek, 2016). Veriler Haziran - Ekim 2020 zaman aralığında sanal ve basılı veri kaynaklarından edinilmiştir. Araştırma verilerinin incelenmesinde betimsel analizden yararlanılmıştır. Betimsel analiz uygulanmasında temel amaç, elde edilen bulguların okuyucuya özetlenmiş ve yorumlanmış bir biçimde sunulmasıdır (Yıldırım ve Şimşek, 2018). Bu bağlamda, bu çalışmada araştırma alanı olarak belirlenen şehirlerde, UCCN Film Alanına ilişkin olduğu belirlenen ikincil verilere betimsel analiz uygulanarak,

IBAD Sosyal Bilimler Dergisi / IBAD Journal of Social Sciences, (Özel Sayı/Special Issue), 2020 
araştırmanın amacı doğrultusunda okuyucuya şehirlerin film alanına kabul edilmek için sahip olmaları beklenen özellikleri taşıma durumları yorumlanarak, özet halinde sunulmuştur.

\section{BULGULAR}

Araştırma evrenini oluşturan 14 şehre ilişkin bulgular alfabetik sıralamaya göre sunulmaktadır.

Aksaray: 1970'li yıllarda Yeşilçam filmlerine ev sahipliği yapan Aksaray'da son zamanlarda daha çok Somuncu Baba, Celaleddin Harzemşah, Komutan, Diriliş Ertuğrul (bir bölümü), Osman, Deliler, Karınca gibi tarihi film ve diziler çekilmektedir. Yerel yönetim, kültürel ve tarihi öneme sahip mekânların canlandırılması için film ve dizi yapımcılarını teşvik etmektedir. Film ve dizi çekimleri için yerel yönetim ve paydaşların desteğiyle Güzelyurt ve Kızılkaya ilçelerinde doğal alanlarda geçici film platoları kurulmuştur (Aksaray Belediyesi, 2020). 1. Ihlara Film Festivali 2015 yılında düzenlenmiş ancak devam etmemiştir (Aksaray Belediyesi, 2015). Aksaray Valiliği (2020), film ve dizi çekimlerini desteklemekte ve tanıtımını yapmaktadır.

Antalya: Uluslararası Antalya Film Festivali, Altın Portakal Film Festivali gibi önemli festivallerin yapıldığı Antalya İli'nde çok sayıda dizi ve film çekildiği görülmektedir (Durmaz, Yigitcanlar ve Velibeyoglu, 2008; Ajanovic ve Çizel, 2015). Büyük Yemin (1969), Alageyik (1969), Berlin Kaplanı, Vatan Sağolsun, Veda, G.O.R.A., Recep İvedik 5, Romantik Komedi-2, Çılgın Dershane 3, Kaybedenler Kulübü Yolda, Ekşi Elmalar (bir kısmı) Antalya'da çekilen yerli filmler arasındadır (Wikipedia, 2020). Antalya, yabancı filmlerin de önemli platolarından biri olmuştur. Criminal Minds: Beyond Borders filmi 2016 yılında Antalya'da çekilmiştir. Avrupanın en büyük film stüdyosu olarak ifade edilen Antalya Film Stüdyosu, henüz kurulum aşamasındadır (Antalya Film Stüdyoları, 2020). Antalya İl Milli Eğitim Müdürlüğü tarafından 7. Ulusal Genç Çınarlar Kısa Film Yarışması, 2019'da Antalya'da düzenlenmiştir. 2016 yılında Alanya Kristal Kale Uluslararası Film Festivali yapılmıştır. Altın Portakal Sinema Okulu, Antalya Film Akademisi gibi sinema ve film ile ilgili eğitim kurumları tarafindan çeşitli etkinlikler düzenlenmektedir (Antalya İl Milli Eğitim Müdürlüğü, 2019; Antalya Altın Portakal Sinema Okulu, 2020). Antalya Büyükşehir Belediyesi, Stratejik Planı, 2015-2019 incelendiğinde film festivalleri (ulusal ve uluslararası) ve film yarışmalarının desteklendiği ve teşvik edildiği görülmektedir (Antalya Büyükşehir Belediyesi, 2014).

Artvin: Doğası ile ön planda olan Artvin'de çekilen Karadeniz dizileri dikkat çekmektedir. Kovan, Yolcu, OHA: Oflu Hoca'yı Aramak, Benim İçin Üzülme, Kalandar Soğuğu, Artvinli, Sevdaluk gibi dizi ve filmlere ev sahipliği yapan il çok sayıda da ziyaretçi almaktadır. Şehirde 2018'de ikincisi düzenlenen Artvin Uluslararası Altın Boğa Doğa Filmleri Festivali organize edilmektedir (T.C. Artvin Valiliği, 2018).

Burdur: Doğal güzellikleri ve bozulmamış kültürü ile doğal bir film platosu olarak ilgi çeken Burdur İli'nde sınırlı sayıda film çekilmiştir. Locman ve Ne Çıkarsa Bahtına Gari filmleri Burdur'da çekilen filmler arasındadır. Burdur'da düzenlenen film festivaline rastlanmamıştır ancak Antalya Altın Portakal Film Festivali Burdur ve Isparta'da da (bazı yıllarda) düzenlenmektedir. 2020 Uluslararası Göç Filmleri Festivali çevrimiçi olarak düzenlenmiştir (T.C. Burdur Valiliği, 2020).

Bursa: Sev Kardeşim, Kış Masalı, Kehribar, Keskin Bıçak, Kınalı Kar (Cumalıkızık), Melekler Adası, Yanık Koza, Al Yazmalım, İstanbullu Gelin, Kuruluş (Cumalıkızı), Dar Alanda Kısa Paslaşmalar, İçerideki (Cumalıkızık), İpekli Mendil gibi birçok dizi ve filme ev sahipliği yapan Bursa İli’nde, Cumalıkızık ilçesi öne çıkmaktadır. Çeşitli sinema etkinlikleri ve film festivallerine de ev sahipliği yapan şehirde, Bursa Film Ofisi ve Film Komisyonu bulunmaktadır (Bursa İl Kültür ve Turizm Müdürlügü, 2019; T.C. Bursa Valiliği, 2019; Bursa Film Komisyonu, 2017).

İzmir: Tarihi, doğal güzellikleri ve iklimi ile dikkat çeken İzmir'de 1960'lardan bu yana 50'yi aşkın dizi ve film çekilmiştir. İzmir Nazım Hikmet Kültür Merkezi'nde Film Yapım Atölyesi (İzmir Nazım Hikmet Kültür Merkezi, 2019) Alsancak’ta Kısa Film Okulu (Kisa Film Okulu, 2019) vb. film, sinema kursu veren kurumlar faaliyet göstermektedir. İzmir'de Uluslararası İzmir Film Festivali, İzmir Kısa Film Festivali, Uluslararası Artemis Film Festivali, Çocuk Filmleri Şenliği, Uluslararası 2 Yaka Kısa Film Festivali gibi uzun süredir düzenli devam eden festival ve etkinlikler bulunmaktadır. İzmir Ateşler İçinde (1959), Zorla Evlendik (1962), Gönül Avcısı (1962), Susuz Yaz (1963), Fıstık Gibi Maşallah (1964), 
Taçsız Kral (1973), Canım Kardeşim (1973), Turist Ömer Uzay Yolunda (1973), Baba Bizi Eversene (1974), Ateş Böceği (1975), Şabaniye (1984), Babam ve Oğlum (2005), Veda (2009), Dedemin İnsanları (2011), Hadi İnşallah (2014), Mucize (2015), Bitmeyen Şarkı (dizi-2010), Fatmagül'ün Suçu Ne? (2010), Kavak Yelleri (2007), Kalbim Ege'de Kaldı (2015), Sen Çal Kapımı (2020) gibi çok sayıda film ve dizi İzmir'de çekilmiştir. Özellikle Seferihisar'da film turizmi faaliyetlerinin gerçekleştiği bilinmektedir (Çelik, 2019). Bununla beraber, İzmir'in UCCN'ye tasarım alanından başvurusu için yerel aktörlerin işbirliğiyle çalışmaların sürdürüldüğü görülmektedir (İzmir Büyükşehir Belediyesi, 2017; Dereli, 2016). Sinema sektöründe istihdamın İzmir'de güçlendirilmesi, gençlerin sinema kariyerlerini yapabilecekleri bir proje geliştirmekle birlikte film çekim ekiplerine fon sağlamak için Sinema İzmir Projesi (Sinema İzmir Fonu) ve Ege Çeşme Projesi kapsamında film platosu kurulması tasarlanmaktadır (İzmir Büyükşehir Belediyesi, 2019).

Karabük: İlde, UNESCO Dünya Miras Listesi'nde bulunan ve tarihi, evleri ve doğasıyla dikkat çeken Safranbolu ilçesi öne çıkmaktadır. Seven Ne Yapmaz, Yamak Ahmet, Erkekler Ağlamaz gibi dizilerle ünlenen Safranbolu'da, 2000 yılından bu yana düzenli olarak Altın Safran Uluslararası Belgesel Film Festivali gerçekleştirilmektedir (Altın Safran Film Festivali, 2019). Ayrıca Halk Eğitim Merkezi’nde, 2017-2018 yılları arasında senaryo yazarlı̆̆ kursu verilmiştir (Safranbolu Kültür Eğitim Merkezi, 2020). Emanetim Safranbolu Belgesel Filmi ve Karımı Gördünüz mü? film galası hakkında bilgi paylaşımı Karabük Valiliği tarafından yapılmıştır (T.C. Karabük Valiliği, 2018; 2019).

Konya: Tarihi ve kültürel yapısı itibariyle tüm dünyanın ilgisini çeken, birçok medeniyete ev sahipliği yapmış Konya ilinde, daha çok tarihi dizi ve filmler çekilmektedir. Direniş Karatay filmi için kurulan film platosu Selçuklu'da bulunmaktadır (KTO Karatay Üniversitesi, 2018). Selçuk Üniversitesi İletişim Fakültesi tarafindan düzenlenen Kısa Film Atölyesi, Uluslararası Öğrenci Filmleri Festivali, Konya Çocuk Film Festivali gibi etkinliklere ev sahipliği yapmaktadır (Konya Çocuk Festivali, 2018; Kısa'ca Film Festivali, 2019).

Mardin: Son Darbe, Salkım Hanım'ın Taneleri, Labirent, Gönül Yarası, Aşka Sürgün, Berivan, Ağa Kızı, Unexpeected (İsveç Yapımı) gibi yerli ve yabancı dizi ve filmler Mardin'de çekmiştir. 2006 yılından itibaren Uluslararası Mardin Festivali düzenlenmektedir. Özellikle yerli dizilerin etkisiyle Mardin'de film turizmi faaliyetlerinin gerçekleştiği görülmektedir (Kervankıran ve Çuhadar, 2017).

Muğla: Şehirde çok sayıda yerli film (Tarkan: Viking Kanı, Bodrum Hakimi, Dondurmam Gaymak, Entelköy Efeköy'e Karşı, Ekşi Elmalar, İftarlık Gazoz, Öldür Beni Sevgilim, 7. Koğuştaki Mucize,) ve yabancı film (Skyfall, The Water Diviner) ve TV programı çekilmiştir. Uzun yıllardır yerli dizilere de (Büyük Yalan, Baba Ocağı, Güzel Köylü, Bir Deniz Hikayesi) ev sahipliği yapan Muğla'da, 2020 yılı itibariyle Kalk Gidelim ve Sefirin Kızı dizilerinin çekimi devam etmektedir. Muğla Uluslararası Film Festivali, Marmaris Uluslararası Film Festivali, Uçan Süpürge Uluslararası Film Festivali, Köyceğiz Kaunos Altın Aslan Türk Filmleri Festivali, Marmaris Uluslararası Kadın ve Sanat Festivali, Marmaris Kısa Film Festivali, Bodrum Çocuk Filmleri Festivali, Uluslararası Göç Filmleri Festivali, Uluslararası İşç Filmleri, Uluslararası Gezici Filmmor Kadın Filmleri Festivali, Uluslararası Bodrum Çevre Filmleri Festivali, Datça Altın Badem Film Festivali, Bodrum Sürdürülebilir Yaşam Kısa Film Festivali, Fethiye Sürdürülebilir Yaşam Kısa Film Festivali gibi çeşitli ulusal ve uluslararası festivallere ev sahipliği yapmaktadır. İlde ayrıca Yılmaz Erdoğan tarafından kurulan bir film platosu ile Muğlalı yönetmen Yüksel Aksu tarafindan eğitim verilen bir Oyunculuk Okulu/Sinema Atölyesi bulunmaktadır. Tarihi, doğal ve kültürel zenginlikleriyle doğal bir film platosu işlevini gören Muğla' da son yillarda film turizmi faaliyetlerinin gerçekleştiği, özellikle yerli dizi çekimlerinin gerçekleştiği ilçelere paket turların düzenlendiği görülmektedir (Saltık, Coşar ve Kozak, 2010; Saltık ve Dönmez, 2020). Muğla Ticaret ve Sanayi Odası, yerel yönetimler, yönetmen ve yapımcılar ile turizm paydaşları tarafindan ulusal ve uluslararası işbirliğine yönelik girişimlerde bulunulduğu da görülmektedir (MUTSO, 2017).

Nevşehir: Doğası ve peri bacaları ile dikkat çeken Kapadokya'da çok sayıda film ve dizi çekimi yapılmıştır. Asmalı Konak, Yer Gök Aşk, Hayalet Sürücü en çok bilinenler arasındadır. Bu sene ilk olarak düzenlenmesi planlanan Kapadokya Turizm Filmleri Festivali organize edilmektedir (Nevşehir Belediyesi, 2020). Nevşehir'de daha çok kültürel ve gastronomi temalı festivaller düzenlendiği görülmektedir (T.C. Nevşehir Valiliği, 2019a; 2019b). 
Rize: Kültürü ve doğasıyla her zaman film ve dizilere, belgesellere konu olan Karadeniz Bölgesi'ndeki ilde; Sevdaluk, Benim için Üzülme gibi diziler çekilmiştir. Çay, Doğa ve Gençlik Filmleri Festivali'nin yanı sıra, her yıl farklı illerde düzenlen Karadeniz Kadın Belgesel Film Günleri (bazı yıllarda) gerçekleştirilmektedir (Rize İl Kültür ve Turizm Müdürlüğü, 2018). Rize Belediyesi Gençlik Merkezi Medya Akademisi'nde senaryo, video, kurgu vb. eğitimler verilmekte ve kısa film yarışması düzenlenmektedir (Rize Belediyesi Gençlik Merkezi ve Bilgi Evi, 2020).

Şanlıurfa: Balıklıgöl, Göbeklitepe, Harran ve Halfeti ile bilinen Şanlıurfa'da Söyleyin Anama Ağlamasın, Bana Git De, Bırakma Beni Eşkıya, Adressiz Sorgular gibi filmler çekilmiş̧tir. 2019 yılı itibariyle Atiye dizisinin çekimleri devam etmektedir. Doğal güzellikleri, tarihi ve kültürel mirası ile önemli değerleri barındıran Şanlıurfa'da, 2019 yılında Uluslararası Göbeklitepe Film Festivali düzenlenmiştir.

Trabzon: Oflu Hocanın Şifresi, Sümela'nın Şifresi, Sen Anlat Karadeniz gibi çeşitli dizi ve filmler Trabzon'da çekilmiştir. Sen Anlat Karadeniz dizisinin hem yurtiçinde hem yurtdışında izlenmesi ve sevilmesiyle Trabzona gelen turist sayısında artış yaşanmıştır (Taş, Başkan ve Taş, 2017). 2017 yılında ilki yapılan Uluslararası Trabzon Film Festivali düzenlenmektedir.

Yukarıda her şehir için ayrı ayrı açıklanmış olan filmlerle ilgili faaliyet bulguları incelenerek, UNESCO yaratıcı şehirler film alanı kriterleri de gözetilmek suretiyle altı grup altında toplanmıştır. Bu gruplar, 1) Ulusal film ve dizi çekimi, 2) Uluslararası film ve dizi çekimi, 3) Film platosunun varlığı, 4) Düzenli veya uzun süreli film festivallerinin olmas1, 5) Film/sinema okulunun olmas1, 6) Yerel yönetimlerin tanıtım çabaları veya bilgi paylaşımları olarak belirlenmiştir. Araştırmada incelenen şehirlerin filmle ilgili faaliyet gruplarını gerçekleştirme/sahip olma durumlarına göre yapılan değerlendirme sonuçları Tablo 4'te sunulmaktadır.

Tablo 4. Şehirlerde Film Faaliyetlerinin Gerçekleştirilme Durumuna İliş̧kin Bulgular

\begin{tabular}{|c|c|c|c|c|c|c|}
\hline Şehir & $\begin{array}{l}\text { 1.Ulusal } \\
\text { Film ve Dizi } \\
\text { Çekimi }\end{array}$ & $\begin{array}{l}\text { 2.Uluslararas } \\
\text { I Film ve Dizi } \\
\text { Çekimi }\end{array}$ & $\begin{array}{l}\text { 3.Film } \\
\text { Platosu } \\
\text { Varlığı }\end{array}$ & $\begin{array}{c}\text { 4.Film } \\
\text { Festivali } \\
\text { (Düzenli/ } \\
\text { Uzun süre) }\end{array}$ & $\begin{array}{l}\text { 5.Film/ } \\
\text { Sinema } \\
\text { Okulu }\end{array}$ & $\begin{array}{c}\text { 6.Yerel } \\
\text { Yönetimin } \\
\text { Tanıtım } \\
\text { Çabaları } \\
\text { /Bilgi } \\
\text { Paylaşımı }\end{array}$ \\
\hline Aksaray & $\checkmark$ & $\mathrm{X}$ & $\checkmark^{* *}$ & $\mathrm{X}$ & $\mathrm{X}$ & $\checkmark$ \\
\hline Antalya & $\checkmark$ & $\checkmark$ & $\sqrt{ }^{*}$ & $\checkmark$ & $\checkmark$ & $\checkmark$ \\
\hline Artvin & $\checkmark$ & $\mathrm{X}$ & $\sqrt{ }$ ** & $\mathrm{X}$ & $\mathrm{X}$ & $\checkmark$ \\
\hline Burdur & $\checkmark$ & $\mathrm{X}$ & $\sqrt{V^{* *}}$ & $\mathrm{X}$ & $\mathrm{X}$ & $\mathrm{X}$ \\
\hline Bursa & $\checkmark$ & $\mathrm{X}$ & $\sqrt{ } \sqrt{* *}^{*}$ & $\checkmark$ & $\checkmark$ & $\checkmark$ \\
\hline İzmir & $\checkmark$ & $\checkmark$ & $\sqrt{ }^{*}$ & $\checkmark$ & $\checkmark$ & $\checkmark$ \\
\hline Karabük & $\checkmark$ & $\mathrm{X}$ & $\sqrt{ }^{* *}$ & $\checkmark$ & $\checkmark$ & $\checkmark$ \\
\hline Konya & $\checkmark$ & $\mathrm{X}$ & $\checkmark$ & $\checkmark$ & $\checkmark$ & $\checkmark$ \\
\hline Mardin & $\checkmark$ & $\checkmark$ & $\sqrt{ } \sqrt{* \star}^{*}$ & $\checkmark$ & $\mathrm{X}$ & $\mathrm{X}$ \\
\hline Muğla & $\checkmark$ & $\checkmark$ & $\checkmark$ & $\checkmark$ & $\checkmark$ & $\checkmark$ \\
\hline Nevşehir & $\checkmark$ & $\checkmark$ & $\sqrt{ } \sqrt{* *}^{*}$ & $\mathrm{X}$ & $\mathrm{X}$ & $\checkmark$ \\
\hline Rize & $\checkmark$ & $X$ & $\sqrt{ }^{* *}$ & $\checkmark$ & $\checkmark$ & $\checkmark$ \\
\hline Şanlıurfa & $\checkmark$ & $X$ & $\sqrt{ }{ }^{* *}$ & $\mathrm{X}$ & $\mathrm{X}$ & $\checkmark$ \\
\hline Trabzon & $\checkmark$ & $\mathrm{X}$ & $\sqrt{ } \sqrt{* *}^{*}$ & $\mathrm{X}$ & $\mathrm{X}$ & $\mathrm{X}$ \\
\hline
\end{tabular}

*Yapım Aşamasında, ** Doğal Film Platosu.

Tablo 4 incelendiğinde, araştırmada incelenen on dört şehrin her birinde en az iki grupta yer alan filmle ilgili faaliyetleri yürüttüğ̈̈ görülmektedir. Buna göre en az sayıda faaliyet yürüten iki şehir, belirlenen faaliyet gruplarından yalnızca ikisini gerçekleştiren Burdur ve Trabzon'dur. Aksaray, Artvin ve 
Şanliurfa'da üç grupta; Mardin ve Nevşehir dört grupta; Bursa, Karabük, Konya ve Rize'de beş grupta; Antalya, İzmir ve Muğla'da ise tüm gruplarda yer alan film faaliyetlerinin gerçekleştirildiği görülmektedir.

Faaliyet gruplanından, ulusal film ve dizi çekiminin yapılmasını kapsayan 1. grup ile (doğal veya yapay) film platosunun varlığını gösteren 3. gruptaki faaliyetlerin tüm şehirlerde gerçekleştirildiği görülmektedir. Yerel yönetimlerin tanıtım çabaları veya bilgi paylaşımları olarak belirlenen 6 . grup faaliyetleri on bir şehirde yürütülmektedir. 4. grubu oluşturan uzun süredir düzenli olarak gerçekleştirilen film festivaline ev sahipliği yapan sekiz şehir vardır. Araştırmada incelenen şehirlerin yarısında, 5. faaliyet grubu olarak belirtilen film/sinema okulu çalışmaları gerçekleştirilmektedir. Gerçekleştirilme oranı en düşük olan film faaliyetleri ise 2. grupta yer alan uluslararası film ve dizi çekimlerinin yapılıyor olmasıdır. Yalnızca beş şehirde uluslararası film ve dizi çekimlerinin yapıldığı görülmektedir.

Araştırma bulguları doğrultusunda ortaya çıkan film faaliyeti grupları, ayrıca Unesco Yaratıcı Şehirler Ağı, film alanı başvuru kriterleri kapsamında değerlendirilmiştir. Değerlendirme sonucunda, filmle ilgili faaliyet gruplarının, UCCN Film Şehri kriter(ler)ini karşılama durumları belirlenmiştir. Bazı faaliyet gruplarınının birden fazla başvuru kriterini karşılamaya tek başına veya diğer gruplarla birlikte katkı sağlıyor olması nedeniyle ilişkilendirme sonucu bir matris formunu almıştır. Tablo 5'te filmle ilgili faaliyet gruplarının, UCCN Film Şehri kriter(ler)ini karşılama durumları yer almaktadır.

Tablo 5. Filmle Ilgili Faaliyet Gruplarının, UCCN Film Şehri Kriter(ler)ini Karşılama Durumları

\begin{tabular}{|c|c|c|c|c|c|c|}
\hline \multirow{2}{*}{ UCCN Film Şehri Kriterleri } & \multicolumn{6}{|c|}{ Filmle İlgili Faaliyet Grupları } \\
\hline & 1 & 2 & 3 & 4 & 5 & 6 \\
\hline $\begin{array}{l}\text { i. Film stüdyoları, film çekimi yapılan alan ve manzaralar vb. } \\
\text { gibi filmle ile ilgili önemli altyapının bulunması }\end{array}$ & $\mathrm{x}$ & $\mathrm{X}$ & $\mathrm{X}$ & & & \\
\hline $\begin{array}{l}\text { ii. Filmlerin yapımı, dağıtımı ve ticarileştirilmesine ilişkin } \\
\text { sürekli veya kanıtlanmış bağlantıların varlığı }\end{array}$ & $\mathrm{X}$ & & $\mathrm{X}$ & & & \\
\hline $\begin{array}{l}\text { iii. Film festivallerine, gösterimlerine ve filmle ilgili diğer } \\
\text { etkinliklere ev sahipliği yapma deneyimi }\end{array}$ & & & & $\mathrm{x}$ & & \\
\hline iv. Yerel, bölgesel ve uluslararası düzeyde işbirliği girişimleri & & $\mathrm{x}$ & & & & \\
\hline $\begin{array}{l}\text { V. Arşivler, müzeler, özel koleksiyonlar ve/veya film } \\
\text { enstitüleri biçiminde film mirasına sahip olması }\end{array}$ & & & & & & \\
\hline vi. Film/sinema okulları ve eğitim merkezleri & & & & & $\mathrm{X}$ & \\
\hline $\begin{array}{l}\text { vii. Yöresel veya ulusal film yapımını ve/veya yönetimini } \\
\text { yaygınlaştırma çabası }\end{array}$ & $\mathrm{x}$ & & & & & \\
\hline $\begin{array}{l}\text { viii. Yabancı filmler hakkında bilgi paylaşımını teşvik eden } \\
\text { çalışmalar }\end{array}$ & & $\mathrm{x}$ & & & & $\mathrm{X}$ \\
\hline
\end{tabular}

Tablo 5 araştırma bulgularında açığa çıkan filmle ilgili faaliyet gruplarının başvuru kriterlerini karşılamadaki etkinlikleri açısından incelendiğinde, bulgularda ortaya çıkan 6 farklı faaliyet grubu içinden 1. grupta yer alan ulusal film ve dizi çekiminin i., ii. ve vii. kriter olmak üzere üç başvuru kriterinin karşılanmasına katkı sağladığı görülmektedir. 2. grubu oluşturan uluslararası film ve dizi çekiminin de i., iv. ve viii. kriterlerin karşılanmasına katkı sağladığı belirlenmiştir. 3.grup olarak belirlenen film platoları i. ve ii. kriter olmak üzere iki kriterin karşılanmasına katkı sağlamaktadır. 4. grubu oluşturan düzenli veya uzun süreli film festivallerinin olması birebir iii. başvuru kriteri ile, 5 . grupta yer alan film/sinema okulunun olması ise birebir vi. başvuru kriteri ile eşleşmektedir. 6. grupta yer alan faaliyetlerin ise viii. başvuru kriterinin karşılanmasına kısmen katk1 sağladığ görülmektedir. Araştırmada, filmle ilgili gerçekleştirildiği belirlenmiş hiçbir faaliyet grubunun v. kriterin karşılanmasına katk1 sağlamadığı anlaşılmıştır.

Bir matris formunda olan Tablo 5'te sunulan bulgular, UCCN film alanı başvuru kriterlerinin karşılanma durumu açısından da yorumlanmıştır. Buna göre başvuru kriterlerinden;

(i) Film ile ilgili altyapı, stüdyolar, film çekimi yapılan alan ve manzaralar vb. olması kriteri, araştırma bulgularında ortaya çıkan 1., 2. ve 3. grupta yer alan unsurların varlığıyla karşılanmaktadır, 
(ii). Filmlerin yapımı, dağıtımı ve ticarileştirilmesine ilişkin sürekli veya kanıtlanmış bağlantıların varlığı kriteri, 1. ve 3. gruptaki film faaliyetleri ile desteklenmektedir,

(iii) Film festivallerine, gösterimlerine ve filmle ilgili diğer etkinliklere ev sahipliği yapma deneyimi kriteri, araştırma bulgularında belirlenen 4. Gruptaki faaliyetlerle yerine getirilmektedir,

(iv) Yerel, bölgesel ve uluslararası düzeyde işbirliği girişimleri kriteri, 2. gruptaki faaliyetler ile kısmen desteklenmektedir,

(v) Arşivler, müzeler, özel koleksiyonlar ve/veya film enstitüleri biçiminde film mirasına sahip olması kriterini karşılamaya yönelik herhangi bir faaliyet grubunun ortaya çıkmadığı görülmektedir,

(vi) Film/sinema okulları ve eğitim merkezleri kriteri, araştırma bulgularında belirlenen 5. Gruptaki faaliyetlerle yerine getirilmektedir,

(vii) Yöresel veya ulusal film yapımını ve/veya yönetimini yaygınlaştırma çabasını işareteden kriter, 1. gruptaki faaliyetler ile kısmen desteklenmektedir,

(viii) Yabancı filmler hakkında bilgi paylaşımını teşvik eden çalışmaları kapsayan kriter, 2. ve 6. faaliyet gruplarıyla kısmen desteklenmektedir.

Bu bağlamda araştırmada incelenen şehirlerin tüm faaliyet gruplarını yürütüyor olsa bile, film alanı başvuru kriterlerinden olan film mirasına ilişkin (arşivler, müzeler, özel koleksiyonlar, film enstitüleri vb.) bir faaliyetin gerçekleştirilmediği bulgusuna ulaşılmıştır.

\section{SONUÇ}

Küreselleşmenin etkisiyle tek tip kültüre evrilmenin önüne geçmek, yerel kültürlere sahip çıkmak, korumak ve sürdürülebilir kılmak için stratejiler geliştirilmektedir. Kültürel ve yaratıcı endüstrilerin katma değerinin yüksek oluşu ve bu doğrultuda bu endüstrilerin, ekonomik kalkınma hızını artırması nedeniyle önemli bir pazar ortaya çıkmıştır. 2004 yılında UNESCO Yaratıcı Şehirler Ağı'ının kurulmasının da etkisiyle son yıllarda yaratıcı endüstrilerin maddi ve maddi olmayan değerlerde ortaya çıkardığı olumlu yansımalar nedeniyle giderek ilgi gördüğü açıktır. UNESCO Yaratıcı Şehirler Ağı kapsamında; edebiyat, film, müzik, zanaat ve halk sanatları, tasarım, gastronomi ve medya sanatları olmak üzere yedi farklı yaratıcı alan belirlenmiştir. Yaratıcı alanlar içinden şehrin kültürel yapısına en uygun alan üzerinden yapılan başvuru ve alınan unvan ile şehrin marka değeri/kimliği kazanması sağlanmaktadır. Türkiye'de 2020 yılı itibariyle film, medya sanatları ve edebiyat alanından başvuru bulunmamaktadır. Özellikle film turizminin son y1llardaki gelişimi de gözetildiğinde, Türkiye'de UNESCO yaratıcı şehirler ağına film alanı üzerinden katılımda yüksek potansiyele sahip şehirler olabileceği öngörülmektedir. Bu bağlamda bu çalışmada Türkiye'deki film çekimlerine yoğun bir şekilde ev sahipliği yapan 14 adet şehrin yaratıcı film şehri olma potansiyelleri ikincil veriler üzerinden incelenmiş̧iir. Araştırmada incelenen şehirler Aksaray, Antalya, Artvin, Burdur, Bursa, İzmir, Karabük, Konya, Mardin, Muğla, Nevşehir, Rize, Şanlıurfa ve Trabzon’dur.

İkincil veri kaynaklarından edinilen verilerin betimsel analiziyle gerçekleştirilen araştırma sonucunda incelenen şehirler, filmle ilgili faaliyetleri gerçekleştirme durumlarına ve bu faaliyetlerin başvuru kriterlerini karşılama durumuna göre değerlendirilmiştir. UNESCO Yaratıcı Şehirler Ağı'na Film Alanından üye olma potansiyelleri incelenen şehirlerde, ulusal film çekimlerinin sayısının yüksek oluşu, şehirlerin doğal film platosu olarak kullanımının yaygınlığı, film temalı festivallerin varlığı ve film çekimleriyle ilgili bilgi paylaşımının yapılması faaliyetlerinin öne çıktığı görülmektedir. Ancak, şehirlerin genelinde film platosu olarak kullanılan alanların şehirlerin doğal peyzajı olduğu, profesyonel anlamda bir film platosuna sahip sınırlı sayıda şehir olduğunu belirtmek gerekmektedir. Araştırmada incelenen tüm şehirlerin yerel yönetimlerinin filmlerle ilgili faaliyetlerin tanıtımı ve bilgi paylaşımı konusunda bir çaba içinde olduğu anlaşılmaktadır. Bununla birlikte belirtilen paylaşımların odağında filmle ilgili faaliyetlerden ziyade ilgili kurum, kişi veya törenlerin olması nedeniyle, film endüstrisine veya film turizmine katkı sağlama konusunda oldukça sınırlı etkiye sahip oldukları görülmektedir. Araştırmada incelenen şehirlerin ancak yarısında film veya sinema eğitimi özel veya kamu kurumları aracılığıyla yürütüldüğü, uluslararası film ve dizi çekimlerine ev sahipliği yapmanın ise en seyrek olarak gerçekleştirilen film faaliyeti olduğu belirlenmiştir. 
Film faaliyetleri gruplarından yalnızca iki tanesini gerçekleştiren, görece daha az sayıda film çekimine ev sahipliği yapan Burdur ve Trabzon'un yaratıcı film şehri olma potansiyellerinin, incelenen şehirler arasında en düşük şehirler olduğu görülmüştür. Aksaray, Artvin ve Şanlıurfa şehirlerinin, Burdur ve Trabzon şehirlerinden daha fazla faaliyeti gerçekleştirmekle birlikte, altı grupta toplanan film faaliyetlerinin ancak yarısını yürüttügü, dolayısıyla başvuru kriterlerini karşılama oranlarının da benzer şekilde düşük kaldığı anlaşılmıştır. Mardin ve Nevşehir şehirlerinin, belirlenen film faaliyetlerinin yarısından fazlasını gerçekleştirmeleri nedeniyle başvuru kriterlerini karşılama oranları da biraz daha yüksektir. Bu nedenle öncesinde belirtilen beş şehre göre, yaratıcı şehirler film alanına daha yatkın olarak değerlendirilmişlerdir. Mardin ve Nevşehir uluslararası film çekimlerine ev sahipliği yapmaları nedeniyle öne çıarken, her iki şehirde film veya sinema eğitiminin verildiği bir kurumun olmaması dikkat çekmektedir. Bursa, Karabük, Konya ve Rize şehirlerinin, araştırmada belirlenen film faaliyetlerinin önemli bir bölümünü kısmen veya tamamen gerçekleştiren şehirler olmaları nedeniyle yaratıcı film şehri olma potansiyellerinin daha yüksek olduğu sonucuna varılmıştır. Bursa ilinde film komisyonunun ve film ile ilgili eğitimlerin, Konya'da Selçuklu Film Platosu ve Film Akademisi'nin varlığı bu iller için önemli üstünlük sağlamaktadır. Bursa, Karabük ve Konya'da, uluslararası film çekimlerinin gerçekleştirilmesinin sağlanması, şehirlerin başvuru kriterlerini karşılama durumlarına katkı sağlayacaktır. Bahsi geçen on bir şehrin dışında kalan üç şehir, araştırmada incelenen altı gruptaki film faaliyetlerini kısmen veya tamamen gerçekleştiren, dolayısıyla başvuru kriterlerini karşılama düzeyleri daha yüksek olan şehirler olarak öne çıkmaktadır. Araştırma sonucunda Yaratıcı Film Şehri olma potansiyelleri yüksek olarak belirlenen bu grupta, Antalya, İzmir ve Muğla şehirleri bulunmaktadır.

Antalya şehri, 1950'lere dayanan film mirası ile uzun süredir yapılan ulusal ve uluslararası festivalleri, uygun doğası, iklimi ve coğrafyası ile film ve dizi çekimlerinin vazgeçilmez yerlerden biridir. Antalya, hali hazırda kıyı turizmi için dünyanın her yerinden turist çekmektedir. UNESCO Film Alanı başvuru kriterleri incelendiğinde Film Şehri unvanı için uygun olduğu görülmektedir. Özellikle uluslararası bir saygınlığa sahip olan Altın Portakal Film Festivali’ne ev sahipliği yapmanın Antalya için üstünlük sağladığı düşünülmektedir. Durmaz, Yiğitcanlar ve Velibeyoğlu (2008) çalışmalarında Antalya İli'nin yaratıcı sektörler içinde film endüstrisi ile ilgili gelişimini ele alarak film endüstrisinde Avrasya için önemli bir film merkezi haline dönüşme potansiyelinin yüksek olduğunu belirtmiş̧ir. Ajanovic ve Çizel (2015) ise, Antalya İli’ni UNESCO Yaratıcı Şehirler Ağı Film Alanı'ndan kabul edilebilirliğine dair çalışmalarında, şehrin film alanından kabul edilme olasılığının yüksek olduğunu vurgulamıştır. $\mathrm{Bu}$ çalışmanın sonucu, araştırma konusuyla ilgili sınırlı sayıdaki araştırmalara uyum göstermektedir.

İzmir için de film alanından başvurunun uygun olduğu gözlemlenmektedir. Film ve sinema okulları, uzun süredir devam eden film ve sinema festival ve etkinlikleri ile birçok film ve diziye ev sahipliği yapmış İzmir'in Film Kenti unvanı için güçlü adaylardan olduğu belirlenmiştir. İzmir'de kamu ve özel sektör temsilcilerinin etkin işbirliği ile film sektörüyle ilgili projelendirme çalışmaları da şehrin film alanından ağa girme potansiyelini artırmaktadır. Bununla birlikte İzmir'in sahip olduğu yaratıcı şehir ağı olma potansiyelini değerlendirerek, Tasarım Kenti unvanı olmayı kendine hedef seçmiş olduğu görülmektedir (İzmir Büyükşehir Belediyesi, 2017; Dereli, 2017).

Muğla şehri, film çekimlerine ev sahipliği yapma tarihi çok eskilere dayanan bir şehirdir. Muğla, tarihi, kültürel ve doğal güzellikleri, elverişli iklimi ve coğrafyası ile ulusal ve uluslararası turizmin önemli merkezlerinden birisidir. Önceleri doğası ve turizm çekicilikleri ile öne çıkan Muğla'nın, son yollarda özgün kültürü, yaşam tarzı ve kültürel değerleri ile ziyaretçileri ve film yapımcılarını etkilediği görülmektedir. Birçok film ve diziye konu veya mekan olan şehirde, destinasyondaki film çekimlerinin artışına bağlı olarak film turizmi faaliyetlerinin de gerçekleştirildiği görülmektedir. Çalışmanın sonucu Muğla'nın film turizmi potansiyelini incelemek üzere gerçekleştirilen ve şehirde çekilen dizi ve filmlerin çokluğuna ve artışına işaret eden çalışmalarla (Saltık, Coşar ve Kozak, 2010; Saltık ve Dönmez, 2020) uyum göstermektedir. Araştırmada incelenen şehirlerin genelinde olduğu üzere Muğla'da da doğal peyzaj yaygın olarak kullanılmaktadır. Ancak şehirde etkin biçimde uluslararası düzeyde faaliyet gösteren bir film platosunun varlığı, Muğla'nın araştırma kapsamında incelenen şehirlere göre bir adım öne çıkmasını sağlamaktadır. 1970'li yıllardan itibaren film, dizi, belgesel çekimlerinin yanı sıra ulusal ve uluslararası çeşitli festivallere ev sahipliği yapmış ve yerel yönetim aktörlerinin konuyla ilgili girişimlerinin söz konusu olduğu Muğla şehrinin, UNESCO Yaratıcı Şehirler Ağı'na Film Alanı üzerinden başvurusunun elverişli olduğu görülmektedir. 
Araştırma sonucunda yaratıcı film şehri olma potansiyeli yüksek olarak belirlenen Antalya, İzmir ve Muğla şehirleri tüm dünyada doğası, denizi ve iklimi ile tanınmaktadır. Kıyı turizmi için önemli destinasyonlardan olan şehirler için uluslararası saygın bir ağa üye olmak, küresel bir unvan kazanmak, kültürel faaliyetleri ve yaratıcılığ 1 teşvik ederek, bölgede kültür turizminin, yaratıcı turizmin yaygınlaşmasını hızlandırmak için önemli adımlardan biri olacaktır. Uluslararası bu ağa katılımla gerçekleşecek tanıtım desteği, destinasyonların deniz, kum ve güneş haricinde kültürünün, yerel mutfağının ve tarihinin daha geniş kitlelere ulaşmasını ve marka değerinin gelişmesine katkı sağlayacaktır. Başvurunun yapılması ve başarılı şekilde sonlanması, turizmin on iki aya yayılması için bir firsat yaratırken, bölgede yaratıcı endüstrilerin ortaya çıkardığı istihdam olanakları ve katma değer ile ekonomik kalkınma desteklenmesi için oldukça önemlidir. Kültürü ve yaratıcıllğı sürdürülebilir kalkınmanın önemli unsuru olarak gören UNESCO Yaratıcı Şehirler Ağı'na film alanından kabul edilmek şehirlerin marka değeri kazanması açısından da önem taşımaktadır. UNESCO Film Şehri unvanını alması, uluslararası, ulusal ve yerel düzeyde bölgenin ve kültürün tanınmasına katkı sağlayacaktır. Böylelikle kültürün nesilden nesle aktarılması sağlanacak, bölge yaratıcıllğa teşvik edilerek, turistik faaliyetler aracılığıyla sürdürülebilir kalkınma desteklenecektir. Yaratıcı şehirler ağına film alanından başvuru kriterlerinin sağlanmasına yönelik gerçekleştirilecek çalışmalar aynı zamanda 2020-2023 Ulusal Akıllı Şehirler Stratejisi ve Eylem Planı'nda (Çevre ve Şehircilik Bakanlığı, 2019) vurgulanan kültür ekonomisinin bileşenlerini içerecek şekilde yaratıcı endüstrilerin geliştirilebileceği ortamların oluşturulmasına, dolayısıyla şehirlerin ulusal stratejilere uyumlu hareket yeteneği kazanımına sağlayacağı katkı nedeniyle önem taşımaktadır. Bunun yanında, yaratıcı şehirler ağına film alanından başvurmak üzere geliştirilecek faaliyetlerin, şehirlerin 11. Kalkınma Planında (2019) vurgulanan kültürel endüstrilerin çeşitlendirilmesi, kültür endüstrileri ve kültürel girişimlere yönelik destek mekanizmalarının geliştirilmesi hedeflerine ulaşılmasında da önemli oranda katkı sağlayabilecek olması, konunun ilgili şehirlerin yönetsel organlarınca dikkate alınmasının gerekliliği ve anlamlılığına işaret etmektedir.

$\mathrm{Bu}$ çalışmada sunulan sonuçlar, yalnızca doküman incelemesi üzerinden elde edilen verilere dayanarak hazırlanmıştır. Çalışmanın en önemli kısıtı, yalnızca ikincil verilere ilişkin bulguları içeriyor olmasıdır. Gelecek araştırmalarda çoklu veri toplama yöntemleriyle veri toplanarak araştırmanın kapsamının genişletilmesi önerilmektedir. Yüz yüze görüşme ve yerinde gözlem gibi derinlemesine bilgi toplanacak araştırma teknikleriyle toplanacak araştırma verileri, çalışmanın ve bulgularının zenginleşmesini sağlayacaktır. Araştırma kapsamında yapılan literatür taramasında, araştırma konusunda yapılmış oldukça sınırlı sayıda çalışmanın yapıldığı görülmüştür. Bu bağlamda uluslararası yazında daha fazla tartışılmaya başlanan, genel olarak yaratıcı şehirler ağı, özel olarak yaratıcı film şehirleri konularının ulusal yazında da farklı kapsam ve yöntemlerle incelenmesinin turizm yazınına katkı sağlayacağı düşünülmektedir. UNESCO önderliğinde gerçekleştirilen ve turizm endüstrisindeki belirgin etkileri nedeniyle öne çıkan önemli uygulamalar olarak Yaratıcı Şehirler Ağı ve Kültürel Miras Listesi oluşumları arasındaki ilişkileri değerlendirmeye yönelik çalışmaların da araştırma konusunun farklı boyutlarıyla incelenmesine olanak sunacağı öngörülmektedir.

\footnotetext{
Bilgilendirme:

Yazarlar aşağıdaki billgillendirmeleri yapmaktadırlar:

1- Araştırmacılar çalışmaya eşit oranda katkı sağlamışlardır.

2- Bu çalışma, 1-2 Eylül 2020 tarihlerinde gerçekleştirilen 5. Uluslararası Bilimsel Araştırmalar E-Kongresi'nde (5th International Scientific Research E-Congress, IBAD-2020) sözlü olarak sunulan ve kongre kitabında özet olarak basılmış olan bildirinin geliştirilmesiyle hazırlanmıştır.

4- Makalenin yazarları arasında çıkar çatışması bulunmamaktadır.

5- Makalemizde ikincil verilerin taranmasıyle elde edilen verilerin incelenmiş olması nedeniyle etik kurulu izni ve/veya yasal/özel izin alınmasını gerektiren bir durum yoktur.

7- Bu makalede araştırma ve yayın etiğine uyulmuştur.
} 


\section{KAYNAKÇA}

Ajanovic, E. ve Çizel, B. (2015). Unesco Yaratıcı Kentler Ağı ile Antalya kentinin değerlendirilmesi. Mediterranean Journal of Humanities, V(1), 1-16.

Akdu, U. ve Akdu, S. (2018). Turizm tanıtımında gastronomik değer vurgusu: UNESCO Gastronomi Şehirleri örneği. Journal of Tourism and Gastronomy Studies, 6(4), 933-952.

Akdu, U. ve Akın, M.H. (2016). Film ve dizilerin destinasyon tercihlerine etkileri. Journal of International Social Research. 9(45), 1042-1052.

Akın, A.G.N. ve Bostancı, A.G.B. (2017). Unesco Yaratıcı Şehirler Ağı kapsamında Gaziantep: Mevcut raporlar bağlamında bir değerlendirme. Sustainable Development, 8(19), 110-124.

Aksaray Belediyesi (2015). 1. Ihlara Film Festivali. 14 Haziran 2020 tarihinde https://www.aksaray.bel.tr/etkinlikler-136/1-ihlara-film-festivali200138 adresinden erişildi.

Aksaray Belediyesi (2020). Aksaray'da çekilen Celaleddin Harzemşah ve Komutan Adlı Dizi ve Filmin Seti. 14 Temmuz 2020 tarihinde https://www.aksaray.bel.tr/haberler-78/belediye-baskani-dincerve-vali-aydogdu-aksarayda-cekilen-celaleddin-harzemsah-ve-komutan-adli-dizi-ve-filmin-setiniziyaret-etti_21-07-2020 adresinden erişildi.

Alyakut, Ö. ve Küçükkömürler, S. (2018, Mart). Kocaeli gastronomi potansiyelinin Yaratıcı Şehirler Ağı kapsamında değerlendirilmesi. Uluslararası Orhan Gazi ve Kocaeli Tarihi- Kültürü Sempozyumu $V$ (s.1779-1804), Kocaeli.

Antalya Büyükşehir Belediyesi, Antalya’ya İyi Gelecek, 2015- 2019 Antalya Büyükşsehir Belediyesi

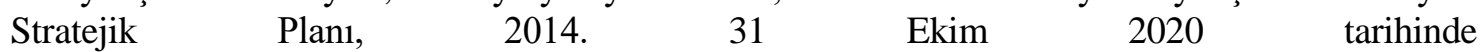
https://antalya.bel.tr/Content/UserFiles/Files/Raporlar\%2FStratejikPlan\%2F20152019_Stratejik_Plan.pdf adresinden erişildi.

Antalya Film Stüdyoları. 16 Haziran 2020 tarihinde http://www.antalyastudios.com/ adresinden erişildi.

Antalya Altın Portakal Sinema Okulu. 30 Ekim 2020 tarihinde https://www.antalyaff.com/tr/page/index/4/102 adresinden erişildi.

Antalya İl Milli Eğitim Müdürlüğü (2019). Ulusal Genç Çınarlar Liseler Arası Film Yarışması. 31 Ekim 2020 tarihinde https://antalya.meb.gov.tr/www/ulusal-genc-cinarlar-liseler-arasi-kisa-filmyarismasinda-oduller-sahiplerini-buldu/icerik/1893 adresinden erişildi.

Arınç, K. (2017). UNESCO Yaratıcı Kentler Ağı için bir öneri: Bitlis gastronomi kenti. Electronic Turkish Studies, 12(29), 87-106.

Aslan, G. (2017). Yaratıcı endüstrilerin yükselişi: Geçmiş, bugün ve gelecek. Anadolu Üniversitesi Sosyal Bilimler Dergisi, 17(4), 109-122.

Beeton, S. (2004). Rural tourism in Australia- Has the gaze altered? Tracking rural images through film and tourism promotion. International Journal of Tourism Research, 6(3), 125-135.

Beeton, S. (2008). From the screen to the field: The influence of film on tourism and recreation, Tourism Recreation Research, 33(1), 39-47.

Bursa İl Kültür ve Turizm Müdürlüğ̈ (2019). 6. Uluslararası Yed-I Vilayet Kısa Fìlm Festivali. 20 Temmuz 2020 tarihinde https://bursa.ktb.gov.tr/TR-243660/6-uluslararasi-yed-i-vilayet-kisafilm-festivali.html adresinden erişildi.

Bursa Film Komisyonu (2017). About us. 20 Temmuz 2020 tarihinde http://bursafilmcommission.com/about-us adresinden erişildi.

Comunian, R. (2011). Rethinking the creative city: The role of complexity, networks and interactions in the urban creative economy. Urban Stud, 48(6), 1157-1179.

Çelik, Ö.Ç. (2019). Film turizmi ve Sığacık’a (İzmir) etkileri. Adıyaman Üniversitesi Sosyal Bilimler Enstitüsü Dergisi, (31), 432-460. 
Department for Digital, Culture, Media and Sport (DCMS). Creative industries mapping document. Department of Culture, Media and Sport, UK, London, 2001. 10 Haziran 2020 tarihinde https://www.gov.uk/government/publications/creative-industries-mapping-documents-2001 adresinden erişildi.

Della Lucia, M. ve Segre, G. (2017) Intersectoral local development in Italy: The cultural, creative and tourism industries. International journal of Culture, Tourism and Hospitality Research, 11(3), 450-462.

De-Miguel-Molina, M., De-Miguel-Molina, B., Santamarina, V. ve Segarra-Oña, M. (2016). Intangible heritage and gastronomy: The impact of UNESCO gastronomy elements. Journal of Culinary Science \& Technology, 14(4), 293-310.

Demirtaş, N. ve Pektaş, K. (2020). UNESCO yaratıcı gastronomi şehri Hatay'ın yerel gastronomi işletmecilerinin bakış açısıyla farkındalık düzeyinin incelenmesi. Türk Turizm Araştırmaları Dergisi, 4(3), 2724-2745.

Dereli, H. C. (2017). Tasarım kenti olmayı hedefleyen İzmir' in zihinsel altyapısını dönüştürmek için bir etkinlik tasarımı önerisi. Yedi Sanat Tasarım ve Bilim Dergisi, 17, 25-38.

Durmaz-Drinkwater, B., Platt, S. veYigitcanlar, T. (2010). Creativity, culture tourism and place-making: Istanbul and London film industries. International Journal of Culture, Tourism and Hospitality Research, 4(3), 198-213.

Durmaz, B, Yigitcanlar, T. ve Velibeyoglu, K. (2008) Creative cities and the film industry: Antalya's transition to a Eurasian film centre. The Open Urban Studies Journal, 1(1), 1-10.

Emmendoerfer, M.L., Emmendoerfer, L. ve Ashton Guerra, M.S. (2016, Haziran). Analysis of the heritage requalification process to the recognition of a UNESCO creative city of gastronomy. Proceedings of TCL 2016 Conference, 163-173, Infota, Budapest, Hungary.

Filming in Turkey. Film Lokasyonlart. 14 Haziran 2020 tarihinde www.filminginturkey.com.tr adresinden erişildi.

Gaziantep Belediyesi (2015). Gaziantep Dünya Gastronomi Şehri oldu. 06 Haziran 2020 tarihinde https://www.gaziantep.bel.tr/tr/haberler/gaziantep-dunya-gastronomi-sehri-

oldu\#: :text=UNESCO\%2C\%20bug\%C3\%BCn\%2033\%20\%C3\%BClkeden\%2047,\%C3\%B6nc \%C3\%BC\%20\%C5\%9Fehir\%20olma\%20\%C3\%B6zelli\%C4\%9Fini\%20kazand\%C4\%B1 adresinden erişildi.

Giritlioğlu, İ., İpar, M.S. ve Karakan, H.İ. (2016). Gastronomi alanında UNESCO Yaratıcı Şehirler Ağı üyeliğinin Gaziantep şehrine olası avantajları üzerine bir araştırma. 3rd International Congress on Social Sciences, China to Adriatic, Congress Book, Antalya.

Gürbüz, S., Serçek, G. Ö. ve Toprak, L. (2017). Mardin'in Unesco yaratıcı şehirler ağında "gastronomi kenti” olabilirliğine ilişkin paydaş görüşleri. Journal of Tourism and Gastronomy Studies, 5(1), 124-136.

Gürbüz, S. ve Şahin, F. (2018). Sosyal bilimlerde araştırma yöntemleri. Ankara: Seçkin Yayıncılık.

Hall, P. (2000). Creative cities and economic development. Urban Studies, 37(4), 639-649.

Hocaoğlu, D. (2015). Yaratıcı endüstrilerin yerel ekonomilerdeki önemi ve tasarımın bu endüstrilere katk1s1. Planlama 2015, 25(3), 189-194.

Işıkman, N.G. (2017). Temel kavramlar ışığında yaratıcı endüstriler. İletişim: Araştırmaları Dergisi, 14, 75-86.

İzmir Büyükşehir Belediyesi (2017). Dünya tasarım başkenti adayları arasına İzmir'de girdi. 24 Temmuz 2020 tarihinde https://www.izmir.bel.tr/tr/Haberler/dunya-tasarim-baskenti-adaylariarasina-izmir-de-girdi/26569/156 adresinden erişildi. 
İzmir Büyükșehir Belediyesi (2019). Başkan Soyer'den sinema sektörüne iki müjde. 30 Ekim 2020 tarihinde https://www.izmir.bel.tr/tr/Haberler/baskan-soyer-den-sinema-sektorune-ikimujde/40881/156 adresinden erişildi.

İzmir Nazım Hikmet Kültür Merkezi. Sinema atölyeleri. 24 Temmuz 2020 tarihinde https://izmir.nhkm.org.tr/sinema-atolyeleri/ adresinden erişildi.

Kervankıran, İ. ve Çuhadar, M. (2017, Ekim). Mardin'de çekilen dizi ve filmlerin yereldeki yansımaları. Vol. 18. 18. Ulusal Turizm Kongresi içinde. 935-942. Ankara: Detay Yayıncılık.

Khoo, S.L. ve Badarulzaman, N. (2014) Factors determining George Town as a city of gastronomy. Tourism Planning \& Development, 11(4), 371-386.

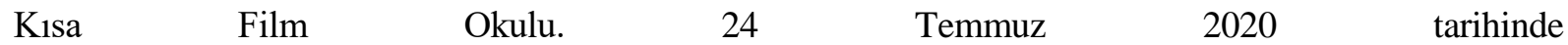
http://kisafilmokulu.com/?fbclid=IwAR2fv0Beru rHPVWRdltAJwwVVMK5c4TWXSArRdRV -dwgw6xSdAT-dFw21w adresinden erişildi.

Kisa'ca Film Festivali. Kısa'ca Film Festivali, 2019. 27 Temmuz 2020 tarihinde http://kisacafilmfestivali.com/ adresinden erişildi.

Konya Çocuk Festivali. Konya Çocuk Festivali, 2018. 27 Temmuz 2020 tarihinde http://www.konyacocukfestivali.com/ adresinden erişildi.

Kütahya Belediyesi (2019). UNESCO Yaratıcı Şehirler A ̆̆ 13. Genel Kurul Toplantısı. 14 Haziran 2020 tarihinde http://www.kutahya.bel.tr/haber.asp?id=3087 adresinden erişildi.

KTO Karatay Üniversitesi (2018). Bilim insanları Direniş Karatay Film Platosu'na hayran kaldı. 30 Ekim 2020 tarihinde https://www.karatay.edu.tr/Haber/bilim-insanlari-direnis-karatay-filmplatosu-na-hayran-kaldi.html adresinden erişildi.

Lee, N. ve Pose, A.R. (2014) Innovation in creative cities: Evidence from British small firms. Industry and Innovation, 21(6), 494-512.

Mutlu, H. (2019). UNESCO Gastronomi alanında rehber kriterlerin Gaziantep gastronomisi açısından değerlendirilmesi. Uluslararası Sosyal Araştırmalar Dergisi, 12(67), 929-936.

Muğla Ticaret ve Sanayi Odası (MUTSO). Muğla Bollywood'a set olacak, 2017. 10 Ağustos 2020 tarihinde http://www.mutso.org.tr/haberler/mugla-bollywooda-set-olacak adresinden erișildi.

Nevşehir Belediyesi (2020). Nevşehir Belediyesi Uluslararası Turizm Filmleri Festivali’ne ev sahipliği yapıyor. 29 Ekim 2020 tarihinde http://www.nevsehir.bel.tr/haber-detay/6379/nevsehirbelediyesi-uluslararasi-turizm-filmleri-festivali-ne-ev-sahipligi-yapiyor adresinden erişildi.

Nižić, BR.K., Rudan, M.E. ve Trinajstić, M. (2019) The role of creative cities in regional development. Poslovna Izvrsnost ZAGREB God XIII, 13(1), 35-54. doi: 10.22598/pi-be/2019.13.1.35.

Popescu, R.I. ve Coboş, R.A. (2012). Creative city and urban development - competitiveness through culture. Sibiu in the context of UNESCO Creative Cities Network. Humanities and Social Sciences Review, 01(02), 491-504.

Rize Belediyesi Gençlik Merkezi ve Bilgi Evi (RIBBEGEM). Kısa Film Yarışması, 2020. 28 Ekim 2020 tarihinde http://www.ribegem.com/1001-gozle-rize-film-festivalinde-atolye-calismalaribasliyor.html adresinden erişildi.

Richards G. (2011). Creativity and Tourism: The state of the art. Annals of Tourism Research, 38(4), 1225-1253.

Richards, G. (2014) Creativity and tourism in the city. Current Issues in Tourism, 17(2), 119-144.

Richards, G. ve Marques, L. (2012). Exploring creative tourism: Introduction. Special Issue of the Journal of Tourism Consumption and Practice, 4(2), 1-11.

Richards, G. ve Raymond, C. (2000) Creative tourism. ATLAS News, 23, 16-20. 
Safranbolu Kültür Eğitim Merkezi. 18 Ağustos 2020 tarihinde http://www.sakem.org/ adresinden erişildi.

Saltık I.A., Cosar, Y. ve Kozak, M. (2010). Televizyon dizilerinin destinasyon pazarlaması açısından olası sonuçları. Anatolia Turizm Araştırmaları Dergisi, 21(1), 41-50.

Saltık, I.A. ve Dönmez, F.G. (2020, Ekim). A model proposal for identifying the relationship between film tourists' motivation, expectations and satisfaction. Conference on Managing Tourism Across Continents. (s. 293-304). (MTCON-2020) Proceedings, Turkey.

Taş, S., Kamber Taş, S. ve Başkan, K. (2017). Turistik Destinasyon tercihlerinde filmlerin ve TV dizilerinin etkisi: Doğu Karadeniz Bölgesi örneği. Journal of International Social Research, 10(54), 1134-1145.

Taştan, H. ve İflazoğlu, N. (2018). Hatay'ın Unesco gastronomi şehri olması ile ilgili yerel restoran işletmelerinin farkındalığının değerlendirilmesi. Journal of Tourism and Gastronomy Studies, 6(3), 384-393.

T.C. Aksaray Valiliği (2020). Aksaray dizi ve sinema filmlerine ev sahipliği yapıyor. 31 Ekim 2020 tarihinde http://aksaray.gov.tr/aksaray-dizi-ve-sinema-filmlerine-ev-sahipligi-yapiyor adresinden erişildi.

T.C. Artvin Valiliği (2018). Artvin 2. Uluslararası Altın Boğa Doğa Filmleri Festivali başladı. 1 Temmuz 2020 tarihinde http://www.artvin.gov.tr/artvin-2-uluslararasi-altin-boga-doga-filmlerifestivali-basladi adresinden erişildi.

T.C. Burdur Valiliğ İ (2020). Göç Filmleri Festivali. 12 Temmuz 2020 tarihinde www.burdur.gov.tr/uluslararasi-goc-filmleri-festivali-merkezicerik adresinden erişildi.

T.C. Bursa Valiliğ̊̆ (2019). Yaşayan Osmanlı köyü Cumalıkızlk. 31 Ekim 2020 tarihinde http://www.bursa.gov.tr/yasayan-osmanli-koyu-cumalikizik. adresinden erişildi.

T.C. Cumhurbaşkanlığı Strateji ve Bütçe Bakanlığı. On Birinci Kalkınma Planı (2019-2023), 2019. 28 Ekim $2020 \quad$ tarihinde https://www.sbb.gov.tr/wpcontent/uploads/2019/07/OnbirinciKalkinmaPlani.pdf adresinden erişildi.

T.C. Çevre ve Şehircilik Bakanlığı. 2020-2023 Ulusal Akıllı Şehirler Stratejisi ve Eylem Planı, 2019. 31 Ekim 2020 tarihinde https://www.akillisehirler.gov.tr/wp-content/uploads/EylemPlani.pdf. adresinden erişildi.

T.C. Karabük Valiliği (2018). “Karımı Gördünüz mü?” film ekibinden Vali Çeber'e ziyaret. 31 Ekim 2020 tarihinde http://www.karabuk.gov.tr/karimi-gordunuz-mu-film-ekibinden-vali-cebereziyaret adresinden erişildi.

T.C. Karabük Valiliği (2019). Emanetim Safranbolu gala gecesi yapıldı. 31 Ekim 2020 tarihinde http://www.karabuk.gov.tr/emanetim-safranbolu-gala-gecesi-yapildi adresinden erişildi.

T.C. Kırşehir Valiliği (2019). UNESCO Kırşehir müziğini tescilledi. 12 Haziran 2020 tarihinde http://www.kirsehir.gov.tr/unesco-kirsehir-muzigini-tescilledi adresinden erişildi.

T.C. Nevşehir Valiliği (2019a). Ürgüp İlçemizde Uluslararası Bă̆ Bozumu Festivali kortej yürüyüşündeyiz. 30 Ekim 2020 tarihinde http://www.nevsehir.gov.tr/urgup-ilcemizdeuluslararasi-bag-bozumu-festivali-kortej-yuruyusundeyiz adresinden erişildi.

T.C. Nevşehir Valiliği (2019b). I. Uluslararası Avanos-Kapadokya Dünya Halk Dansları Festivali katılımcılarından valilik ziyareti. 31 Ekim 2020 tarihinde http://www.nevsehir.gov.tr/iuluslararasi-avanoskapadokya-dunya-halk-danslari-festivali-katilimcilarindan-valilik-ziyareti adresinden erişildi.

T.C. Rize İl Kültür ve Turizm Müdürlüğü (2019). Çay, Doğa ve Gençlik Filmleri Festivali Kısa Film Yarışması. 15 Ağustos 2020 tarihinde www.rize.ktb.gov.tr/TR-215527/cay-doga-ve-genclikfilmleri-festivali-kisa-film-yarism-.html adresinden erişildi. 
Uluslararas1 Altın Safran Film Festivali. 18 Ağustos 2020 tarihinde https://altinsafran.org/tr/belgeselfilm-yarismasi/ adresinden erişildi.

United Nations Development Programme (UNDP). The sustainable development goals report, 2017. 6 Haziran 2020 tarihinde https://www.undp.org/content/undp/en/home/librarypage/sustainabledevelopment-goals/un-sustainable-development-goals-report-2017.html adresinden erişildi.

UNESCO (2006, Ekim). Towards sustainable strategies for creative tourism, discussion report of the planning meeting for 2008. International Conference on Creative Tourism, Santa Fe, New

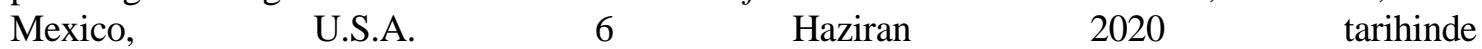
http://unesdoc.unesco.org/images/0015/001598/159811e.pdf. adresinden erişildi.

United Nations Educational, Scientific and Cultural Organizations (UNESCO). The creative cities network: a global platform for local endeavour, 2014. 14 Haziran 2020 tarihinde http://www.unesco.org/fileadmin/MULTIMEDIA/HQ/CLT/pdf/Creative_cities_brochure_en.pdf adresinden erişildi.

United Nations Educational, Scientific and Cultural Organizations (UNESCO). UNESCO creative cities network annual meeting, 2015. 6 Haziran 2020 tarihinde http://en.unesco.org/creativecities/sites/creative- cities/files/List\%20of\%20UNESCO\%20Creative\%20Cities_May2015.pdf adresinden erişildi.

United Nations Educational, Scientific and Cultural Organizations (UNESCO). Global report on culture for sustainable urban development. culture: urban future -key resource for sustainable urban development, 2016.2020 Haziran tarihinde unesdoc.unesco.org/images/0024/002459/245999e.pdf adresinden erişildi.

United Nations Educational, Scientific and Cultural Organizations (UNESCO). UNESCO creative cities network (uccn) "building a collective vision for the future" strategic framework, 2017. 6 Haziran 2020 tarihinde https://en.unesco.org/creative-cities/sites/creative-cities/files/Strategicframework_UCCN.pdf adresinden erişildi.

UNESCO Afyonkarahisar gastronomi şehri. 6 Haziran 2020 tarihinde https://gastroafyon.org/ adresinden erişildi.

UNESCO Busan City of Film. UNESCO creative cities of film. 25 Ekim 2020 tarihinde http://www.unescobusan.org/eng/contents/view.do?mId=41 adresinden erişildi.

UNESCO Cities of Film Network. Cities of film. 31 Ekim 2020 tarihinde https://citiesoffilm.org/\# adresinden erişildi.

UNESCO creative cities network. 14 Haziran 2020 tarihinde http://www.unesco.org/new/en/culture/themes/creativity/creative-cities-network/about-creativecities adresinden erişildi.

UNESCO Hatay gastronomi şehri (2017). Hatay gastronomi şehri. 14 Haziran 2020 tarihinde www.hataygastronomi.com adresinden erişildi.

UNESCO yaratıcı şehirler ağı. 12 Ağustos 2020 tarihinde https://en.unesco.org/creative-cities/creativecities-map adresinden erişildi.

Wikipedia. Antalya' da çekilen dizi ve filmler. 16 Ağustos 2020 tarihinde https://tr.wikipedia.org/wiki/Kategori:Antalya\%27da_\%C3\%A7ekilmi\%C5\%9F_filmler adresinden erişildi.

Yalçın B., ve Turan C. (2018). Creative cities network for marketing touristic products: An analysis on literary cities. Journal of Tourism, Culture and Territorial Development Almatourism, 9(18), 135149.

Yencken, D. (1988). The creative city. Meanjin, 47(4), 597-608. 
Yencken, D. (2013). Creative cities. Space place and culture by future leaders. 1-21. 6 Haziran 2020 tarihinde https://www.futureleaders.com.au/book_chapters/pdf/Space-Place-Culture/DavidYencken.pdf. adresinden erişildi.

Yetkin, K. M. (2019). UNESCO Yaratıcı Kentler Ağı müzik kenti kriterleri bağlamında Şanlıurfa'nın müzik kenti olarak değerlendirilmesi. Yayımlanmamış yüksek lisans tezi, Harran Üniversitesi, Şanliurfa.

Yıldırım, A. ve Şimşek, H. (2018). Sosyal bilimlerde nitel araştırma yöntemleri. Ankara: Seçkin Yayıncilik.

Yu, C., ve Sun, R. (2019). The role of Instagram in the UNESCO's creative city of gastronomy: A case study of Macau. Tourism Management, 75, 257-268. 